\title{
Construcción de un mínimo fraseológico locucional: desde el nivel A hasta el nivel C de español
}

\author{
María Pilar Valero Fernández
}

Valero Fernández, M. P. (2021). Construcción de un mínimo fraseológico locucional: desde el nivel A hasta el nivel C de español. Revista de Filología y Lingüística de la Universidad de Costa Rica, 47(1), e44384. doi: https://doi.org/10.15517/rfl.v47i1.44384

\section{(ㄷ) $\mathbb{P Q}(\mathrm{EY}$}

Doi: https://doi.org/10.15517/rfl.v47i1.44384

URL: https://revistas.ucr.ac.cr/index.php/filyling/index 
Lingüística

Construcción de un mínimo fraseológico locucional: desde el nivel A hasta el nivel C de español

\title{
Construction of a Phraseological Minimum: From The Level A to The Spanish Level C
}

\author{
Valero Fernández, María Pilar
}

\author{
iD María Pilar Valero Fernández \\ Pilar.Valero@uclm.es \\ Universidad de Castilla-La Mancha, Ciudad Real, \\ España
}

Revista de Filología y Lingüística de la Universidad de Costa Rica

Universidad de Costa Rica, Costa Rica

ISSN: 0377-628X

ISSN-e: $2215-2628$

Periodicidad: Semestral

vol. 47 , núm. 1,2021

filyling@gmail.com

Recepción: 27 Enero 2020

Aprobación: 03 Marzo 2020

URL: http://portal.amelica.org/ameli jatsRepo/125/1251597035/index.htm

DOI: https://doi.org/10.15517/rfl.v47i1.44384
Resumen: La enseñanza del español como lengua extranjera (ELE) se enfrenta todavía a diversos enigmas sin resolver. Uno de ellos versa sobre la falta de precisión en la enseñanza de la fraseología, pues en el momento actual se desconoce qué unidades fraseológicas (aquí reducidas a las locuciones) se han de abarcar en el aprendizaje en función del nivel del estudiante; al igual que no existe una instrucción concisa referente al subtipo de locución que tiene que estar presente en cada nivel lingüístico. Por ello, el objetivo del presente artículo es mostrar qué criterios se han seguido para el diseño de un mínimo fraseológico locucional ad hoc así como las unidades fraseológicas (locuciones) que lo integran para los distintos niveles comunes de referencia del MCER. Como resultado, se obtienen 39 locuciones para el nivel A1-A2, 407 para el nivel B1-B2 y 843 para el nivel C1-C2.

Palabras clave: fraseología, locuciones, ELE, mínimo fraseológico, niveles comunes de referencia.

Abstract: The teaching of Spanish as a foreign language (ELE) still confronts various unresolved enigmas. One of them deals with the lack of precision in the teaching of the phraseology, given the fact that at the present time it is unknown what phraseological units (here reduced to the idioms) have to be included in the learning according to the student's level; besides the inexistence of instruction related to the subtype of idioms that has to be present in each linguistic level. Thus, the aim of this paper is to show what criteria has been followed for the design of a phraseological minimum $a d h o c$, as well as the units (idioms) that are part of it for the different common reference levels of the CEFR. As a result, 39 idioms are obtained for level A1-A2, 407 for level B1-B2 and 843 for level C1-C2.

Keywords: phraseology, idioms, ELE, phraseological minimum, levels.

\section{INTRODUCCIÓN}

En la docencia de español como lengua extranjera (ELE) se ha detectado una falta de precisión en torno a la selección de locuciones en función del nivel de dominio lingüístico del alumnado. Dicho de otro modo, 
dependiendo del manual empleado en la enseñanza de ELE, el listado propuesto de locuciones (pónganse de ejemplo, meter la pata, por los siglos de los siglos o de perros) varía sustancialmente tanto en el número como en los exponentes lingüísticos elegidos.

Esta realidad, si se examinan dos obras esenciales para la enseñanza de ELE, el Marco común de referencia para el aprendizaje, la enseñanza y la evaluación (MCER) (Consejo de Europa, 2001 [1 ${ }^{\text {a ed.], }} 2018$ [2a ed.]) y el Plan Curricular del Instituto Cervantes (PCIC) (Instituto Cervantes, 2006), se justifica debido a la tenue importancia otorgada a las locuciones y a otras unidades fraseológicas ${ }^{1}$ en dichas obras de referencia ${ }^{2}$. Concretamente, si la mirada se dirige hacia el $M C E R$, vemos cómo el conocimiento fraseológico se diluye entre la competencia lingüística, la sociolingüística y la pragmática, en particular, "para aquellos usuarios que se encuentren en los estadios de dominio (C1) o maestría (C2)" (Velázquez Puerto, 2018, p. 22). Por su lado, en el $P C I C$, se halla un liviano rastro de las locuciones a lo largo del componente pragmático-discursivo y el nocional de sus respectivos niveles lingüísticos (López Vázquez, 2011; Muñoz-Basols, 2016; Velázquez Puerto, 2018).

Desde el terreno lexicográfico y, en especial, gracias a los diccionarios de Penadés Martínez (DICLOCVER, DICLOCADV y DICLOCNAP) se dispone de un inventario de locuciones verbales, adverbiales, nominales, adjetivas y pronominales que podrían trabajarse en la enseñanza de ELE desde el nivel B1. Asimismo, en este estudio se persigue proponer, a partir de una metodología propia y desde el nivel A1, un conjunto de locuciones que podrían tenerse en cuenta según el estadio lingüístico del estudiante, así como el subtipo de locución (verbal, adjetival, adverbial, etc.).

En vínculo con la fraseodidáctica ${ }^{3}$ en el área de ELE, además, se está trabajando con el fin de aportar unos criterios que guíen al docente en la selección de qué locuciones se han de enseñar, entendiéndolas como el conjunto mínimo representativo de locuciones vinculadas con cada nivel lingüístico de los estudiantes de español, así como en los retos que supone el hecho de introducirla en el aula y en la forma más oportuna de realizarlo (Forment Fernández, 2000; Gómez Molina, 2000; Fernández Prieto, 2004; Pérez Bernal, 2005; Olímpio de Oliveira Silva, Penadés Martínez y Ruíz Martínez, 2006; Solano Rodríguez, 2007; Leal Riol ${ }^{4}$, 2011; González Rey, 2012; Timofeeva, 2013; Aguilar Lozano5, 2013; Penadés Martínez, 2012, 2015, 2017; Núñez Román, 2015; Szyndler, 2015; Velázquez Puerto, 2018; entre otros).

Ante este contexto, se ha optado por la constitución de unos parámetros que han originado el denominado Mínimo fraseológico locucional de ELE (MFLELE), siendo este el reflejo directo de la tesis doctoral (2015-921) desarrollada en la Universidad de Zadar (Croacia) desde el 2016 hasta el 2019. En la redacción del MFLELE, desde el nivel acceso hasta el nivel maestría, se ha creído esencial el trabajo expuesto tanto en el PCIC, pese a ser una obra no prescriptiva, como en la treintena de manuales puestos a examen en esta investigación. Esto es, en el MFLELE se aboga por la manifestación de un número representativo y significativo de locuciones, actuales y frecuentes del español peninsular que han de ser efectivas en el conocimiento fraseológico de los discentes de ELE. En concreto y tras la puesta en marcha de cuatro criterios, en oposición a los demoscópicos, el MFLELE se configura de 39 locuciones en el nivel A, 407 en el nivel B y 843 en el nivel C. Así pues, cabe especificar que en esta investigación se apuesta por la división tripartita amplia de los niveles comunes de referencia A (A1-A2), B (B1-B2) y C (C1-C2).

\section{Precedentes del MFLELE}

Los primeros pasos hacia la confección de un mínimo fraseológico vinieron de la mano de una de sus subdisciplinas, la paremiología ${ }^{6}$, la cual alcanzó un gran desarrollo en destacados estudios rusos en la centuria pasada. Particularmente, no es de extrañar que este primer avance fuera dado por paremiólogos rusos dado el interés que siempre despertó la fraseología (en sentido ancho) entre los investigadores de nacionalidad rusa, como en su momento fue el legado aportado por Polivanov y Vinogradov. 
En particular, entre los años de 1968 y 1969, según se explicita en Zurdo Ruiz-Ayúcar y Sevilla Muñoz (2016, p. 21), el paremiólogo ruso Levin, en su obra Überlegungen zur demoskopischen Parömiologie [Reflexiones sobre paremiología demográfica] sobre reflexiones paremiológicas, dibujó las primeras pinceladas hacia la marcación de aquellas paremias alemanas que gozaban de vigencia y popularidad en la década de los 70 del siglo pasado. Lo que supuso, en cierta medida, el discernimiento de las paremias ya caídas en el olvido de las que su presencia era efectiva. Este hecho, también, dio lugar a la creación de uno de los criterios principales si se desea construir un mínimo.

Unos años más tarde, en 1985, otro paremiólogo ruso, Permiakov, realizaría ya la construcción de un propio mínimo paremiológico en su obra 300 obshcheupotrebitel'nkh russkikh poslovits i pogovorok (dlia govoriashchikh na nemetskom iazyke) [ 300 proverbios y refranes rusos comunes (para hablantes de alemán)], compuesta por 300 paremias populares de la lengua rusa a partir de una metodología basada en la estadística de frecuencia para la selección de dichas unidades (Sevilla Muñoz, 1996, p. 654).

Asimismo, entre las referencias bibliográficas extraídas de la Biblioteca fraseológica y paremiológica del CVC(Centro Virtual Cervantes), a la labor de Permiakov continuarían otros trabajos, como el de Barulin (1984) para el ruso, el de Baur para el alemán (1996), el de Čermak (2003) para el checo, el de Franceschi (1996) para el italiano o el de Arnaud (1992) para el francés, entre otros, en lo que a mínimo paremiológico se refiere. Eso sí, como se comprobará en las líneas siguientes, hay que destacar el trabajo incentivado por el grupo de Investigación Internacional, UCM 930235 Fraseología y Paremiología, integrado por un vasto equipo de paremiólogos de varios países (Vyshnya, 2008, p. 102; Sevilla Muñoz, 2010, p. 233).

En lo que compete a la lengua española, es también en el plano de paremiología donde se atisban los primeros resultados fructíferos de mínimos. De hecho, se ha de subrayar el magnífico trabajo impulsado por Sevilla Muñoz y Zurdo Ruiz-Ayúcar, principales investigadoras del grupo mencionado. Dichas estudiosas han recopilado aquellas paremias ${ }^{7}$ del español estándar que se mantienen vigentes en el momento actual, así como las de alta frecuencia en textos literarios (Sevilla Muñoz, 2010, p. 239). Además, las autoras han mantenido la perspectiva interlingüística, aspecto fundamental del objetivo primario que confirma el potencial de su trabajo, pues junto con el español, "en mayor o menor medida, ya se ha establecido el mínimo paremiológico para el alemán, el búlgaro, el croata, el checo, el eslovaco, el esloveno, el francés, el griego, el húngaro, el inglés y el serbio" (Zurdo Ruiz-Ayúcar y Sevilla Muñoz, 2016, p. 17). La metodología usada en el Minimo paremiológico parte de la realización de encuestas, la revisión de fuentes escritas y orales, el trabajo con informantes, en concreto, denominados por las investigadoras como "la última generación refranera", y la interpretación de índices de frecuencia. En el prólogo de esta obra, Mieder ya anima a futuros investigadores en la construcción de un mínimo paremiológico que aglutine también aquellas paremias del español características de las zonas de Sudamérica, de Centroamérica y de Estados Unidos con el fin de confeccionar un mínimo paremiológico del mundo hispanohablante (Mieder, 2016, pp. 9-10).

Por su parte, Barani (2007), fruto de su investigación doctoral, proporcionó cuáles eran los refranes más frecuentes en español con un fin didáctico enfocado a estudiantes iraníes de español como lengua extranjera. Para este objetivo, su corpus se constituyó de aquellos refranes aparecidos en las colecciones más representativas de refranes, de aquellos refranes presentes en el periódico nacional El País (2000-2001) y de la realización de encuestas orales. El resultado de dicho corpus fue la consideración de los 50 refranes más reiterados del español actual con su correspondencia en la lengua persa.

En relación con los refranes y con la finalidad puesta en la enseñanza de ELE, Penadés Martínez, Penadés Martínez, Xiaojing y Olímpio de Oliveira Silva (2008) ofrecieron también una recopilación de 70 paremias destinadas a estudiantes de nivel avanzado C1-C2 y elaboradas a partir del mínimo paremiológico y aquellas unidades que, según Campo Martínez (2001) y Tarnovska (2005), se consideraban adecuadas para dicha enseñanza. En forma de diccionario ${ }^{8}$, en esta obra Penadés Martínez et al. (2008) aunaron 70 refranes para la enseñanza del español "aprovechables" en el aula, que aparte del significado parafraseado con oraciones de fácil comprensión ${ }^{9}$, aportan la información sobre la función pragmática (tales como, consejo, advertencia, 
entre otras), ejemplos de uso, variedades hispanoamericanas, así como sus correspondencias en inglés, chino y portugués.

Ruiz Martínez (2005), sin hacer referencia explícita a la construcción de un posible mínimo para la enseñanza de unidades fraseológicas (UF) en el contexto de ELE, especificó cuáles serían las UF que podrían abarcarse en los niveles A2 y B1 en vínculo directo entre las funciones comunicativas establecidas por el MCER y el Repertorio de funciones comunicativas del español: niveles umbral, intermedio y avanzado de Gelabert (1996). En este trabajo, se listan un conjunto de locuciones (adjetivas, adverbiales, interjectivas y verbales) y fórmulas oracionales frecuentes que podrían trabajarse en el aula. Se podría decir que, por esta razón, es uno de los trabajos más próximo al MFLELE a pesar de presentar un material fragmentario, tanto a nivel lingüístico como a nivel funcional.

En última instancia, las obras lexicográficas DICLOCVER (2002), DICLOCADV (2005) y DICLOCNAP (2008) de Penadés Martínez, como se apreciará seguidamente, se juzgan como referencias lexicográficas fundamentales con las que el MFLELE está estrechamente vinculado, puesto que, además de tratarse de tres diccionarios en los que se recogen las locuciones que podrían ser objeto de enseñanza en ELE desde el nivel B1, en nuestro trabajo se opinan fuentes modélicas en la lematización de las locuciones.

\section{Fuentes PARA LA CONSTRUCCión DEL MFLELE}

Con el objetivo de proporcionar un corpus fraseológico locucional representativo de cada una de las tres etapas de aprendizaje, es decir, usuario básico (A1-A2), independiente (B1-B2) y competente (C1-C2), se determinó imprescindible la consulta de dos tipos de fuentes para la extracción de las locuciones incluidas en cada nivel:

1. manuales de ELE de las principales editoriales españolas

2. los exponentes incluidos en Nociones Generales, Nociones especificas y Tácticas y estrategias pragmáticas de los diferentes niveles del PCIC

Su consideración no es otra que la de ofrecer un repertorio de locuciones que, efectivamente, sea apropiado al contexto educativo de nuestro interés: la enseñanza de español orientada al estudiante de ELE y no la de un nativo. Consecuentemente, no podemos obviar que el manual como herramienta de aprendizaje, a priori, representa un gran peso para el alumnado a lo largo de todo su progreso lingüístico. De igual manera, el $P C I C$ ha de suponer una obra de referencia en la selección de contenidos por parte de todos los agentes implicados en la enseñanza de ELE (profesores y editores, principalmente). Consecuentemente, se descartaron otras fuentes para el compendio del MFLELE, tales como los diccionarios generales o especializados y las respectivas locuciones recopiladas en sus macroestructuras, o entrevistas orales a hablantes nativos de español.

Asimismo, en cuanto a los manuales, 30 obras en total para los tres niveles de lengua, se acotó el campo de estudio al trabajo desempeñado por siete editoriales españolas: Anaya, Difusión, Edelsa, Edinumen ${ }^{10}$, enClave, SGEL y SM. Los manuales empleados, a su vez, se caracterizaron por estar publicados en la última década, a excepción de dos, el manual En Acción 2 (2005) y El Ventilador (2006). En la Tabla 1 se puede observar el listado de manuales revisados para cada uno de los niveles: 
TABLA 1.

Listado de manuales por nivel

\begin{tabular}{|c|c|}
\hline $\begin{array}{l}\text { Nivel A1-A2 } \\
\qquad(10 \\
\text { manuales })\end{array}$ & $\begin{array}{l}\text { Aula Internacional } 1 \text { (2013), Aula Internacional 2 (2013), Nuevo Sueña } 1 \\
\text { (2015), Embarque } 1 \text { (2011), Embarque } 2 \text { (2011), Nuevo ELE inicial } 1 \\
\text { (2009), Nuevo ELE inicial 2 (2010), En Acción } 1 \text { (2010), Nuevo Español } \\
\text { en marcha } 1 \text { (2017) y Nuevo Español en marcha } 2 \text { (2015). }\end{array}$ \\
\hline $\begin{array}{l}\text { Nivel B1-B2 } \\
\qquad(13 \\
\text { manuales })\end{array}$ & $\begin{array}{l}\text { Aula Internacional } 3 \text { (2014), Aula Internacional } 4 \text { (2014), Aula } \\
\text { Internacional } 5 \text { (2014), Nuevo Sueña } 2 \text { (2015), Nuevo Sueña } 3 \text { (2016), } \\
\text { Embarque } 3 \text { (2014), Embarque } 4 \text { (2014), Nuevo Ele intermedio } 3(2001), \\
\text { Nuevo Ele avanzado } 4 \text { (2002), En acción } 2 \text { (2005), En acción } 3 \text { (2010), } \\
\text { Nuevo Español en marcha } 3 \text { (2014) y Nuevo Español en marcha } 4 \text { (2014). }\end{array}$ \\
\hline $\begin{array}{l}\text { Nivel C1-C2 } \\
\text { (7 manuales) }\end{array}$ & $\begin{array}{l}\text { Nuevo Sueña } 4 \text { (2017), Método } 5 \text { (2017), El ventilador (2006), C de Cl } \\
\text { (2017), Vitamina Cl (2016), Nuevo Prisma Cl (2012) y Nuevo Prisma C } \\
\text { (2012). }\end{array}$ \\
\hline
\end{tabular}

\section{Criterios para la construcción del MFLELE}

Una vez descritas las herramientas consultadas para la confección del MFLELE, se continúa con la presentación de qué pautas se siguieron para su configuración definitiva.

En vínculo con los manuales, se encuentran dos criterios: el criterio (1), basado en la extracción de todas las locuciones halladas en los 30 manuales inspeccionados para los distintos niveles lingüísticos, y el criterio (2), fundamentado en la recopilación, ahora, exclusiva y única de aquellas locuciones con explotación didáctica en dichos manuales. Por consiguiente, tras la aplicación del criterio (2) los resultados se vieron reducidos con respecto al primer criterio.

Por otra parte, en relación con el $P C I C$, está el criterio (3), consistente en la extracción de todas las locuciones presentes en esta obra.

Por último, se sitúa el criterio (4), apoyado en el registro de las locuciones resultantes de los criterios (2) y (3) en las obras lexicográficas de referencia tomadas en esta investigación. En otras palabras, las locuciones que configuran el MFLELE cuentan con la garantía de que los diccionarios DLE (2014), Clave (2012), DFDEA (2018), DICLOCVER (2002), DICLOCADV (2005) y DICLOCNAP (2008) las consideran categorialmente de este tipo y, por consiguiente, quedan desvinculadas de otras unidades fraseológicas, como colocaciones o refranes, entre otras opciones.

En conclusión, se debe clarificar que, si bien los criterios (1) y (2) son vinculantes por ser el resultado directo de la exploración de los 30 manuales de ELE, el criterio (3) es independiente de los dos anteriores, dado su vínculo al PCIC. Así pues, primeramente, las locuciones tuvieron que superar bien los criterios (1) y (2), bien el criterio (3); y, en segundo lugar, todas las locuciones finales tuvieron que sortear el criterio (4) para formar parte del MFLELE.

Así se observa gráficamente en la Figura 1: 


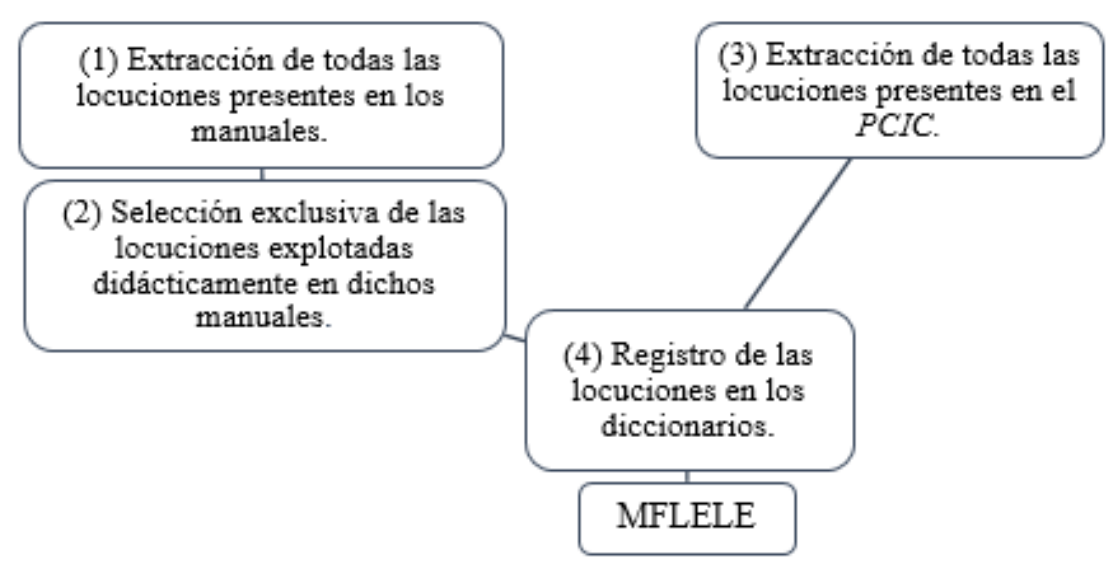

FIGURA 1.

Criterios del MFLELE

Se detallan, a continuación, los cuatro criterios de forma pormenorizada, al mismo tiempo que se incluyen los resultados cuantitativos del MFLELE.

\subsection{Criterio 1: extracción de las locuciones en los manuales}

Al considerar el manual como el instrumento de enseñanza más inmediato en una institución de enseñanza acreditada, como ya se ha adelantado, este supuso una de las fuentes primarias del MFLELE. Su justificación es obtener un corpus real de locuciones que se ajuste a la realidad con la que trabajan los docentes en su aprendizaje diario; al mismo tiempo que se da por hecho que los exponentes lingüísticos manifestados en los manuales se ajustan a voces actuales, frecuentes y de vigencia en el español peninsular. Como consecuencia, en aquellas ocasiones en las que se divisó una locución propiamente de otra variedad no peninsular del español, se elidió por sobrepasar los límites de la investigación.

Previamente, la fraseógrafa Penadés Martínez ya había señalado la conveniencia de un barrido de manuales en la creación de diccionarios de aprendizaje para lograr un lemario significativo, finalidad que se persigue en el MFLELE. En efecto, se observa así en las palabras de la autora: "piénsese, por ejemplo, en la posibilidad de vaciar manuales de español como lengua extranjera, si sus aprendices y los profesores que les imparten docencia van a ser los usuarios de la obra lexicográfica" (Penadés Martínez, 2015, p. 94).

Fruto de la ejecución de este primer criterio, se presenta el número de locuciones obtenidas por nivel y por manual en la Tabla 2 (referente al nivel A1-A2), en la Tabla 3 (en vínculo con el nivel B1-B2) y en la Tabla 4 (en relación con nivel C1-C2), respectivamente. 
TABLA 2.

Número de locuciones registradas por manual. Nivel A1-A2

\begin{tabular}{|c|c|c|c|c|c|c|c|c|c|c|}
\hline & 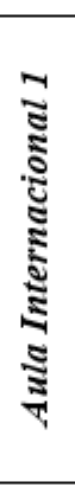 & 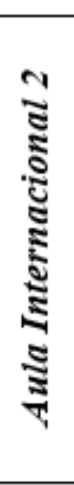 & 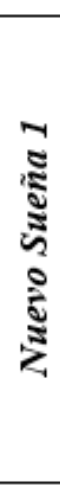 & 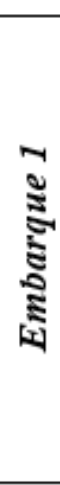 & 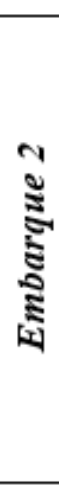 & 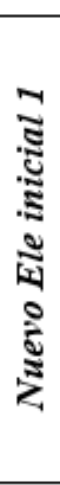 & 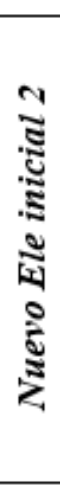 & 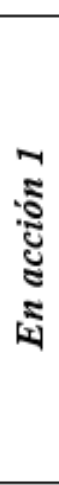 & 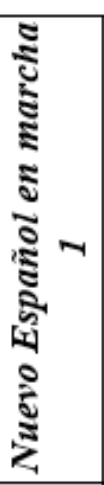 & 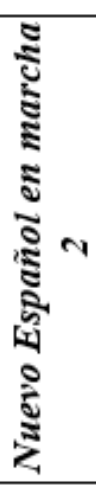 \\
\hline $\begin{array}{c}\mathrm{N}^{0} \mathrm{de} \\
\text { locuciones }\end{array}$ & 12 & 17 & 20 & 13 & 23 & 7 & 13 & 19 & 11 & 21 \\
\hline
\end{tabular}

TABLA 3.

Número de locuciones registradas por manual. Nivel B1-B2

\begin{tabular}{|c|c|c|c|c|c|c|c|c|c|c|c|c|c|}
\hline & 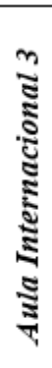 & 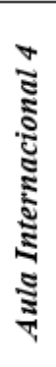 & 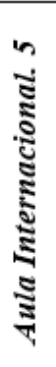 & 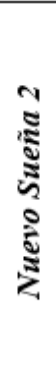 & 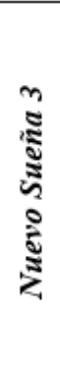 & 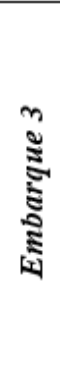 & 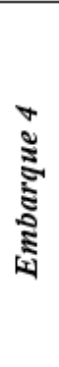 & 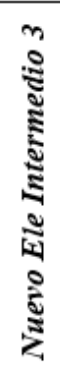 & 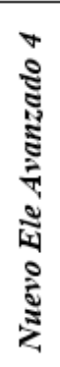 & 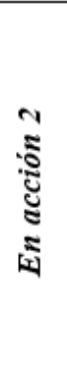 & 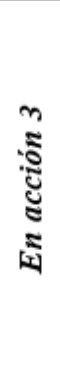 & 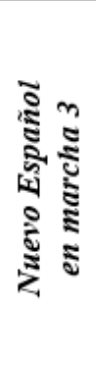 & 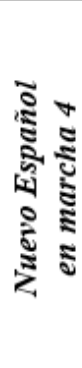 \\
\hline $\begin{array}{c}\mathrm{N}^{\circ} \mathrm{de} \\
\text { locuciones }\end{array}$ & 36 & 38 & 41 & 38 & 46 & 31 & 38 & 45 & 25 & 28 & 52 & 32 & 27 \\
\hline
\end{tabular}

TABLA 4.

Número de locuciones registradas por manual. Nivel C1-C2

\begin{tabular}{|c|c|c|c|c|c|c|c|}
\hline & 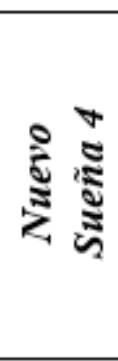 & 水 & 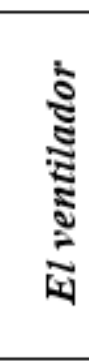 & 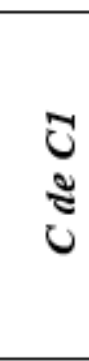 & 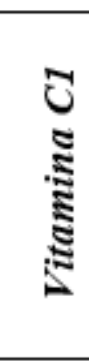 & 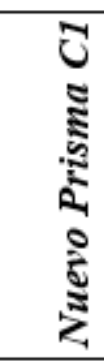 & 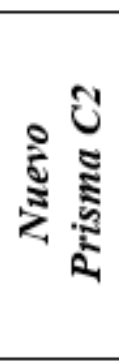 \\
\hline $\begin{array}{c}\mathrm{N}^{\circ} \text { de } \\
\text { locuciones }\end{array}$ & 71 & 183 & 87 & 98 & 64 & 87 & 98 \\
\hline
\end{tabular}




\subsection{Criterio 2: explotación didáctica de las locuciones en los manuales}

Las locuciones resultantes del criterio (1) pasaron un nuevo filtro, reflejo directo del trabajo realizado por las editoriales en el tratamiento de las locuciones. Así, las locuciones extraídas se clasificaron en tres categorías: locución presentada (LP), locución explotada didácticamente (LED) y locución no presentada (LNP). Con respecto a este criterio, cabe ultimar que, para el ingreso de una locución en el último criterio, en el (4), esta ha de tener presencia y explotación en, al menos, uno de los manuales de su correspondiente nivel lingüístico. Se describen las tres circunstancias posibles seguidamente:

- Se entendió por $L P$ aquella que se halló en un determinado manual, pero sobre la que no recayó ningún tipo de explotación didáctica. Así ocurrió con locuciones encontradas en diálogos, textos culturales ${ }^{11}$, enunciados de ejercicios, audiciones, ejemplos, títulos de unidades, cuadros-resumen, etc. La función de las $L P$ se equiparó con un mero apoyo contextual y pragmático. Dicho de otro modo, se consideró una $L P$ aquella cuya aparición fue no intencional y, por consiguiente, no requerida en la enseñanza de ELE de manera activa. En la Tabla 5 se plasman todos los contextos en los que una locución se categorizó como meramente presentada:

TABLA 5.

Contextos relativos a las LP

\begin{tabular}{|l|ll|}
\hline & - & diálogos \\
& - & enunciados de ejercicios \\
& - & textos de cualquier naturaleza \\
& - & audiciones \\
& - & infografias \\
& - & fráficas \\
& - & ejemplos \\
& - & cuadros-resumen \\
& - & esquesarios \\
& - & plogs \\
& - & correos electrónicos \\
& & \\
\hline
\end{tabular}

- Por otro lado, una locución atendió la etiqueta de $L E D$ si recibió alguna explotación (desde una práctica controlada hasta otra libre) enfocada a la forma o al sentido. En efecto, estas locuciones fueron las únicas que lograron superar el criterio (2), pero quedaron a expensas de librar el criterio (4).

Con el fin de reflejar qué casos se creyeron que una locución merecía ser catalogada como $L E D$, en la Tabla 6 se exponen las prácticas didácticas tanto de comprensión como de producción de una locución que dieron lugar a ello. 
TABLA 6.

Actividades de LPED

\begin{tabular}{|c|c|}
\hline 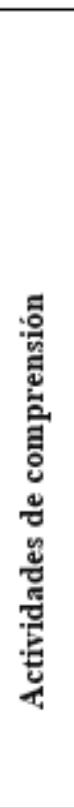 & $\begin{array}{l}\text { - Actividades para relacionar la locución con su correspondiente significado } \\
\text { (por ejemplo, en un audio se escucha una locución y el estudiante ha de elegir } \\
\text { su correspondiente significado). } \\
\text { - Actividades para completar un texto o frases con la locución correcta entre } \\
\text { diferentes opciones dadas. } \\
\text { - Actividades para completar una parte de la locución (por ejemplo, la } \\
\text { preposición o el verbo correctos) entre diferentes opciones dadas. } \\
\text { - Actividades para relacionar la locución con la imagen correcta que represente } \\
\text { tal locución. } \\
\text { - Actividades de lectura de un texto o frases para la posterior explicación del } \\
\text { significado de una locución. } \\
\text { - Actividades para relacionar dos partes de una misma locución. } \\
\text { - Actividades para ordenar las locuciones en función de un determinado criterio } \\
\text { (por ejemplo, según el grado de humor que expresen). } \\
\text { - Actividades de clasificación de locuciones en función de su significado (por } \\
\text { ejemplo, valor positivo frente al negativo). } \\
\text { - Actividades de sustitución de locuciones por una unidad monoléxica (por } \\
\text { ejemplo, sustituir una locución adverbial por su correspondiente adverbio). } \\
\text { Actividades de formación de frases relacionando elementos de diferentes } \\
\text { columnas. }\end{array}$ \\
\hline 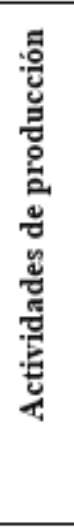 & $\begin{array}{l}\text { - Actividades para describir, oral o por escrito, una determinada circunstancia } \\
\text { por medio del uso de locuciones. } \\
\text { - Actividades de memorización y posterior (re)producción oral/escrita de un } \\
\text { listado de locuciones. } \\
\text { Actividades de búsqueda en el diccionario de una locución para una posterior } \\
\text { producción oral/escrita de un determinado aspecto (por ejemplo, del } \\
\text { significado concerniente a una locución). } \\
\text { - Actividades de producción de textos o frases usando determinadas locuciones } \\
\text { en contexto. } \\
\text { - Actividades de interpretación de gráficos, por ejemplo, por medio del uso de } \\
\text { locuciones. } \\
\text { - Actividades de reflexión lingüística (por ejemplo, sobre el nivel de lengua al } \\
\text { que una locución pertenece). }\end{array}$ \\
\hline
\end{tabular}

Para proceder de manera análoga al criterio (1), en la Tabla 7 se anota la cantidad de locuciones explotadas didácticamente en el nivel A1-A2 para cada uno de los manuales; en la Tabla 8 y en la Tabla 9, se hace lo propio con el nivel B1-B2 y C1-C2, respectivamente. 
TABLA 7.

Número de locuciones explotadas por manual. Nivel A1-A2

\begin{tabular}{|c|c|c|c|c|c|c|c|c|c|c|}
\hline & 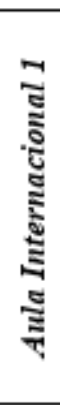 & 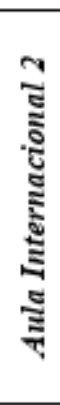 & 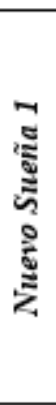 & 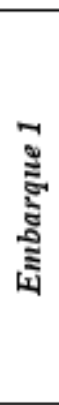 & 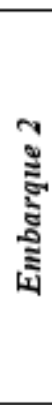 & 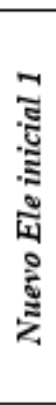 & 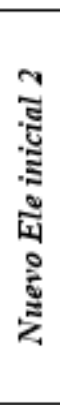 & 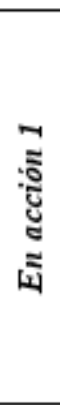 & 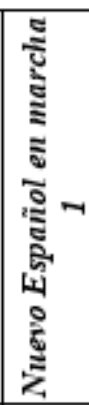 & 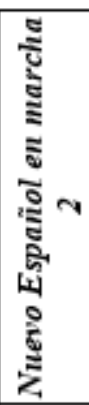 \\
\hline $\begin{array}{c}\mathrm{N}^{\circ} \text { de } \\
\text { locuciones }\end{array}$ & 11 & 13 & 19 & 13 & 9 & 10 & 3 & 10 & 14 & 10 \\
\hline
\end{tabular}

TABLA 8.

Número de locuciones explotadas por manual. Nivel B1-B2

\begin{tabular}{|c|c|c|c|c|c|c|c|c|c|c|c|c|c|}
\hline & 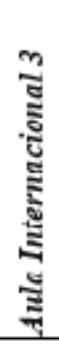 & 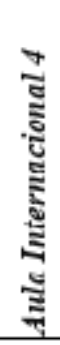 & 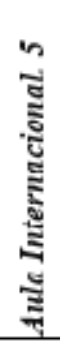 & 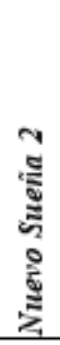 & 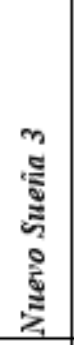 & 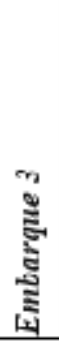 & 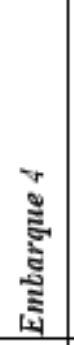 & 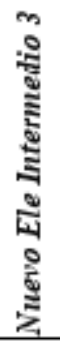 & 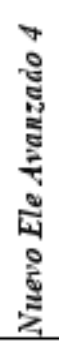 & 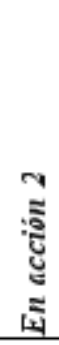 & 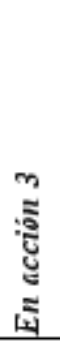 & 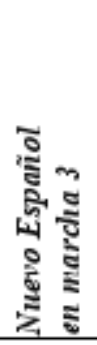 & 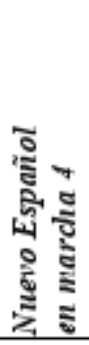 \\
\hline $\begin{array}{c}\mathrm{N}^{\circ} \mathrm{de} \\
\text { locuciones }\end{array}$ & 15 & 29 & 28 & 23 & 121 & 78 & 85 & 25 & 40 & 41 & 76 & 34 & 69 \\
\hline
\end{tabular}

TABLA 9.

Número de locuciones explotadas por manual. Nivel C1-c2

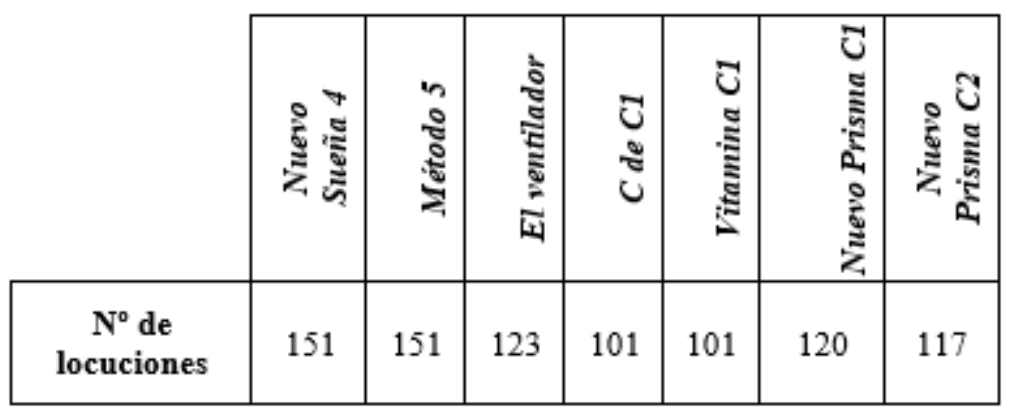

- En última instancia, aquella locución que recibió la leyenda $L N P$ significó que no se contempló en la revisión de un manual. 


\subsection{Criterio 3: extracción de todas las locuciones del PCIC}

El criterio (3) se equiparó con la inscripción de todas aquellas locuciones sugeridas en los inventarios propuestos por el PCIC: $₫ 6$. Tácticas y estrategias pragmáticas, $₫ 8$. Nociones Generales y $\$ 9$. Nociones específicas. Además, el criterio (3) se mantuvo autónomo de los criterios (1) y (2); al igual que estos del PCIC. Es decir, pudo darse la circunstancia de que una locución fuera incluida (tras superar el criterio (4)) y apareciera solamente trabajada en uno de los manuales; o, por el contrario, que una locución de manera exclusiva apareciera en el $P C I C$ y no fuera explotada didácticamente en los manuales seleccionados. Esta segunda circunstancia se examinó de manera muy puntual, ya que se verificó que las empresas editoriales tendieron a reflejar las sugerencias del $P C I C$.

Asimismo, se ha de poner de relieve que, tras el examen minucioso del PCIC, se constató afortunadamente que la enseñanza no se focaliza en unidades aisladas (monoverbales), sino que se tiende a la consideración de construcciones pluriverbales, entre las que se hallan las locuciones. Las locuciones recopiladas del PCIC se localizan en la Tabla 10.

TABLA 10.

Número de locuciones del PCIC

\begin{tabular}{|c|c|c|c|}
\cline { 2 - 4 } \multicolumn{1}{c|}{} & A1-A2 & B1-B2 & C1-C2 \\
\hline $\begin{array}{c}\mathbf{N}^{\circ} \mathbf{d e} \\
\text { locuciones }\end{array}$ & 11 & 138 & 486 \\
\hline
\end{tabular}

\subsection{Criterio 4: registro lexicográfico}

La última prueba que tuvieron que superar las locuciones, bien tomadas de la fuente editorial, bien tomadas del PCIC, fue la de los diccionarios. De este modo, todas las locuciones del MFLELE tuvieron que tener presencia en, al menos, dos de las cinco obras lexicográficas seleccionadas ya citadas anteriormente: $D L E$ (2014), Clave (2012), DFDEA (2018), DICLOCVER (2002), DICLOCADV (2005) y DICLOCNAP (2008). Cabe advertir que, precisamente, la sistematización final del MFLELE, tras la aplicación de este cuarto criterio, fue la labor más ardua de ejecutar.

De esta forma, el registro de las locuciones en los diccionarios se consideró crucial, ya que condicionó la forma en la que finalmente las locuciones aparecen en el MFLELE. Es decir, el hecho de que exista la posibilidad de tener casos en los que bien podemos dar cuenta de una locución con o sin su verbo (obsérvese el contraste de irse de copas frente a de copas), modifica los resultados categoriales del MFLELE, concretamente, del número de locuciones verbales o adverbiales halladas según el nivel de dominio de la lengua.

En específico, el registro lexicográfico de las locuciones estuvo determinado por tres escenarios: i) la discrepancia habitual, en lo que respecta a la forma de hacer referencia a una locución, entre el trabajo expuesto por las editoriales en los manuales y lo que reflejan los diccionarios; ii) el desacuerdo entre los resultados hallados en el PCIC y la labor defendida en los repertorios lexicográficos; y iii) la divergencia en la lematización de las locuciones entre los propios diccionarios.

Así pues, la falta de sintonía entre las fuentes consultadas se simplifica en los siguientes hechos: la cuestionada consideración de determinadas unidades incluidas en el MFLELE como propiamente locuciones (pónganse de muestra \{hablar/llamar/tratar\} de usted o en voz alta), el trato heterogéneo de las variantes léxicas de las locuciones (véanse los casos de tirar la toalla y su variante de arrojar la toalla o de vez en cuando 
y su variante de vez en vez), el tratamiento dispar sobre aquellas locuciones que presentan una preposición en su término (por ejemplo a favor en contraste con a favor de) o, por último, la incorporación u omisión del verbo de una determinada locución (verbigracia estar con la soga al cuello frente a con la soga al cuello).

\section{Resultados del MFLELE}

Una vez que las locuciones vencieron los cuatro principios descritos, se diseñó el MFLELE. Ahora, se detallan los resultados de los tres niveles establecidos ( $\mathrm{A}, \mathrm{B}$ y $\mathrm{C}$ ).

\subsection{Resultados del MFLELE para el nivel A}

Finalmente, en el nivel A, 39 locuciones lograron pasar los cuatro criterios mencionados y conformar el MFLELE (A1-A2). Ahora bien, según la categoría locucional, entre las 39 locuciones totales se discernieron: 17 locuciones adverbiales, 8 locuciones preposicionales, 6 locuciones adjetivas, 6 locuciones verbales y 2 locuciones con doble naturaleza categorial, adjetival y adverbial. Por el contrario, no alcanzaron superar los criterios impuestos ninguna locución nominal, pronominal o conjuntiva. Por otra parte, se ha de precisar que, de las 39 locuciones definitivas, solo 11 locuciones se anotaron en el PCIC (criterio 3 del MFLELE), pero todas con presencia en los distintos manuales.

Igualmente, cabe destacar la presencia reiterada de las 39 locuciones en los manuales a diferencia de lo acontecido en los niveles $\mathrm{B}$ y $\mathrm{C}$, en los cuales los datos obtenidos fueron más divergentes. De esta forma, las locuciones referidas a nociones del espacio referenciales (al lado, debajo de, detrás de, alrededor de, etc.), a la forma de cocinar (a la plancha o al vapor), a la expresión de frecuencia (a menudo o a veces), a los medios de transporte (a pie), a la expresión de opinión (a favor, en contra o de acuerdo) y a las distintas formas de hablar (en voz baja, en voz alta, en público o en privado) fueron una constante en los manuales. Llamó incluso la atención en la semejante forma de explotar didácticamente las locuciones, en especial, las referidas a las nociones espaciales.

\subsection{Resultados del MFLELE para el nivel B}

En el nivel B o intermedio un cómputo definitivo de 407 locuciones logró llegar hasta el último criterio del MFLELE. Como se verifica al comparar estos resultados con los del MFLELE anterior, en el nivel de usuario independiente la cuantía de locuciones se aumentó de manera precipitada. Además del crecimiento del número de locuciones registradas, se ha de poner en relieve que en este nivel ya tuvieron cabida todos los tipos locucionales, aunque de forma desequilibrada si se compara el peso otorgado a las locuciones adverbiales o verbales frente a las nominales o pronominales. De esta forma, las 407 locuciones se distribuyeron categorialmente en: 185 adverbiales, 107 verbales, 35 preposicionales, 25 adjetivas, 18 conjuntivas, 14 nominales, 1 pronominal, 20 adjetivas/adverbiales ${ }^{12}, 1$ adverbial/preposicional y 1 adverbial/nominal.

En cuanto a la concurrencia de locuciones en el PCIC, en sintonía con lo expresado por los manuales, la cifra de locuciones proliferó en contraste con el nivel A. Así, se hallaron 138 locuciones. Entre ellas estuvieron: por adelantado (loc. adv.), puesto que (loc. conj.), un montón (loc. nom.), tenerlugar (loc. verb.), respecto a (loc. prep.), del tiempo (loc. adj.) o en contra (loc. adj./adv.). No se tuvo noticia de ninguna locución pronominal, por el contrario.

Si en el nivel A nos enfrentamos a una tendencia evidente por las locuciones transparentes o con poca carga idiomática (por ejemplo, \{hablar/llamar/tratar\} de tú, en casa o de noche); contrariamente, en el nivel $\mathrm{B}$ se constató que esta preferencia quedó en un segundo plano. Así, tuvieron una influencia destacable las locuciones idiomáticas o translaticias en vínculo con las diferentes nociones sugeridas en el PCIC para 
este nivel (a cántaros, a pierna suelta, de uvas a peras o entre Pinto y Valdemoro). Junto con las locuciones idiomáticas descritas, se distinguieron también por su trato regular en los manuales aquellas locuciones adverbiales con valor de conector discursivo (tales como en \{primer/segundo/tercer\} lugar, no obstante o sin embargo), las locuciones conjuntivas (véanse mientras que, siempre y cuando o ya que) y las preposicionales (piénsense respecto a, pese a o gracias a). Sin embargo, en la inclusión de otros tipos de locuciones, como las nominales (por ejemplo, agua pasada o agua de borrajas), las verbales (como aburrirse como una ostra o \{apretar/clavar/hincar/romperse\} los codos) o las pronominales (como ni pío), se divisó un registro más heterogéneo o aleatorio en función del manual revisado.

\subsection{Resultados del MFLELE para el nivel C}

En el nivel $\mathrm{C}$ o en el de usuario competente, se descubrió un salto cuantitativo en el número de locuciones. Para ser exactos, se duplicó el total de locuciones respecto al nivel B. Por ende, fueron 843 las locuciones que formaron el Mínimo del nivel C. En cuanto a su clasificación por el subtipo de locución, estas se distribuyeron en: 347 adverbiales, 294 verbales, 35 preposicionales, 49 adjetivas, 23 conjuntivas, 26 nominales, 4 pronominal, 64 adjetivas/adverbiales ${ }^{13}$ y 1 adverbial/preposicional.

En el PCIC las locuciones encontradas fueron 486 de las 843 . Este dato vino a apoyar la preponderancia que se da en los niveles superiores a la fraseología y, en particular, a las locuciones (Gutiérrez Quintana, 2004; Penadés Martínez, 2004). Entre ellas, se localizaron: tocar madera (loc. verb.), si bien (loc. conj.), a borbotones (loc. adv.), por culpa de (loc. prep.), pelos y señales (loc. nom.), (ni) un alma (loc. pron.) o a salto de mata (loc. adj./adv.). Ahora bien, la revisión del PCIC no trajo pocos problemas a la hora de homogeneizar la forma lexicalizada en él y el paso de una determinada locución por el criterio (4). A modo de ejemplo, en el PCIC se registró andar a salto de mata; en cambio, el modo lematizado en los diccionarios fue el de a salto de mata y, como consecuencia, como locución adjetiva/adverbial y no como verbal.

\section{Mínimo fraseológico locucional de ELE}

En última instancia, se exponen las locuciones que forman el Mínimo fraseológico locucional de ELE, según los tres niveles lingüísticos del MCER: A (A1-A2), B (B1-B2) y C (C1-C2).

\subsection{MFLELE para el nivel A}

a continuación
a favor
al aire libre
a la plancha
al lado
alrededor de
al vapor
a menudo
a pie
a tiempo
a veces
caer $\{$ bien $/ \mathrm{mal}\}$
cerca de
de acuerdo




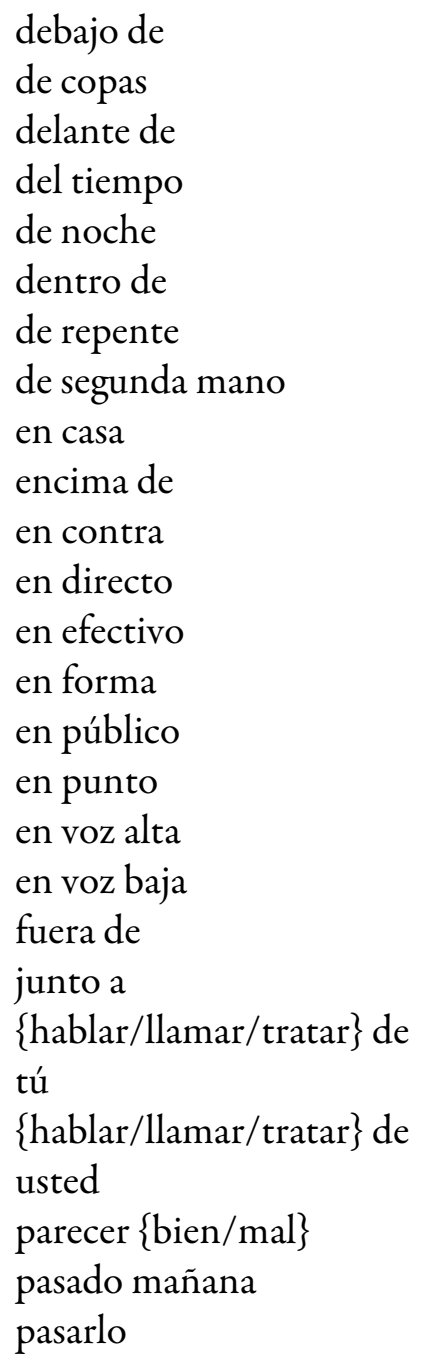

\subsection{MFLELE para el nivel B}

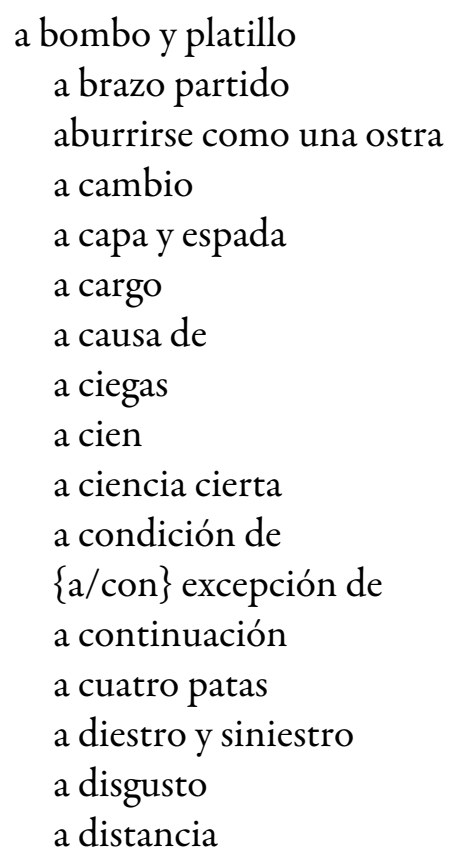




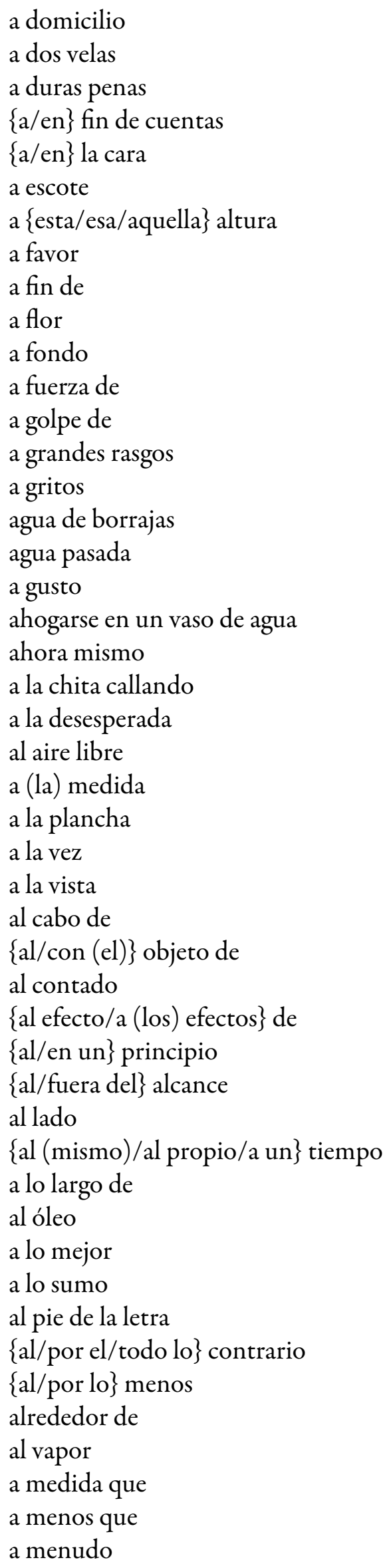




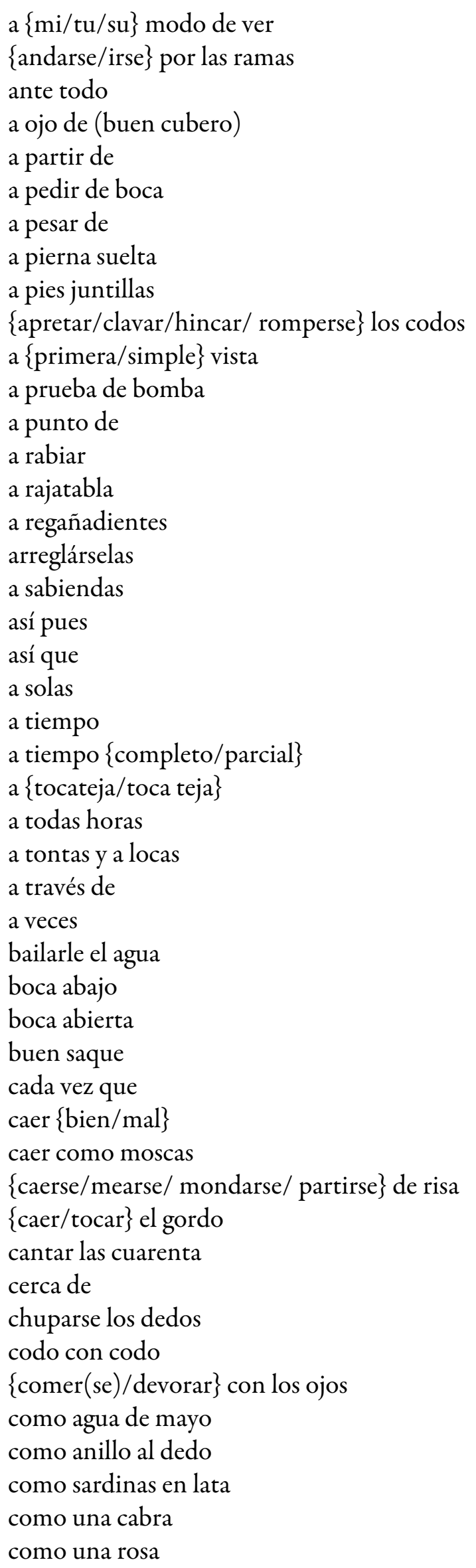




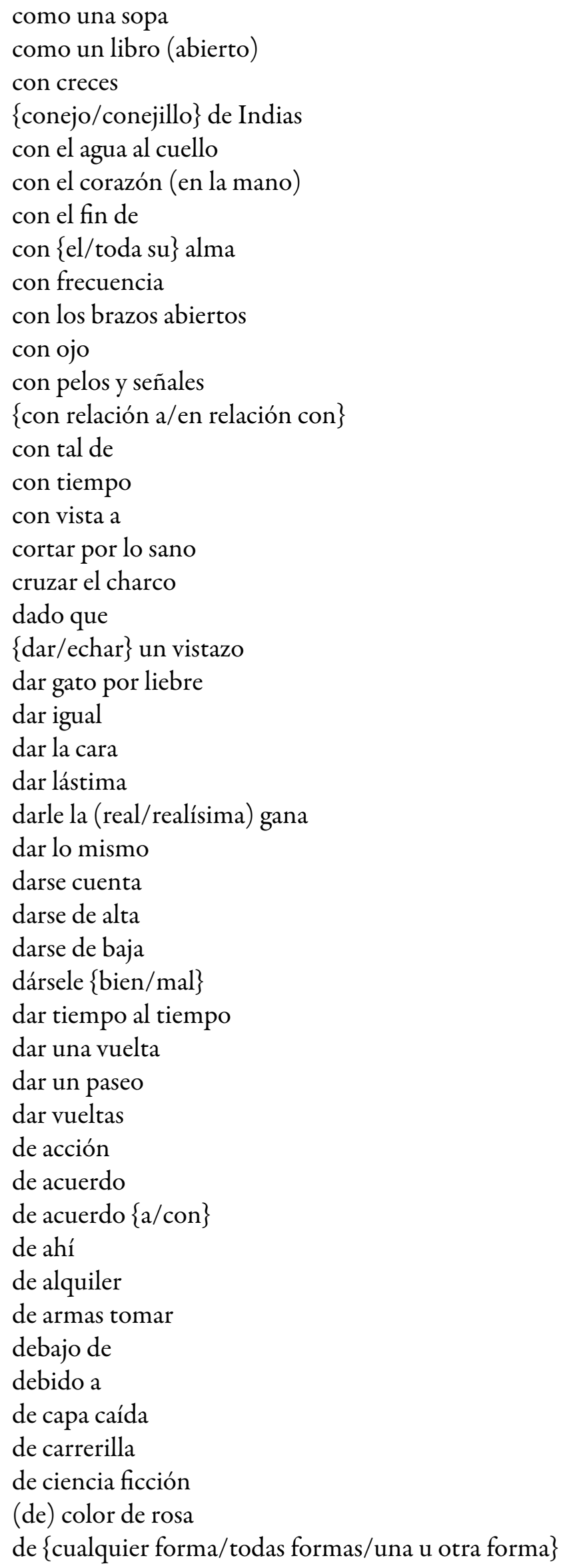


de $\{$ cualquier manera/todas (las) maneras\}

de cuando en cuando

de día

$\{$ de/en\} broma

de espaldas

de forma que

de frente

de golpe

de gorra

de hecho

de hierro

de lado

delante de

del tiempo

de madrugada

de mal en peor

de manera que

de mano

de más

de miedo

de moda

de modo que

de morros

de ninguna manera

de ningún modo

de noche

dentro de

de nuevo

de oídas

de pacotilla

$\{$ de/para $\}$ andar por casa

de Pascuas a Ramos

de perfil

de perilla

de $\{\mathrm{pie} / \mathrm{s}\}$

de pronto

de repente

de punta en blanco

de raíz

de rodillas

desde luego

de segunda mano

de sol a sol

de terror

de un tirón

de uvas a peras

de verdad 


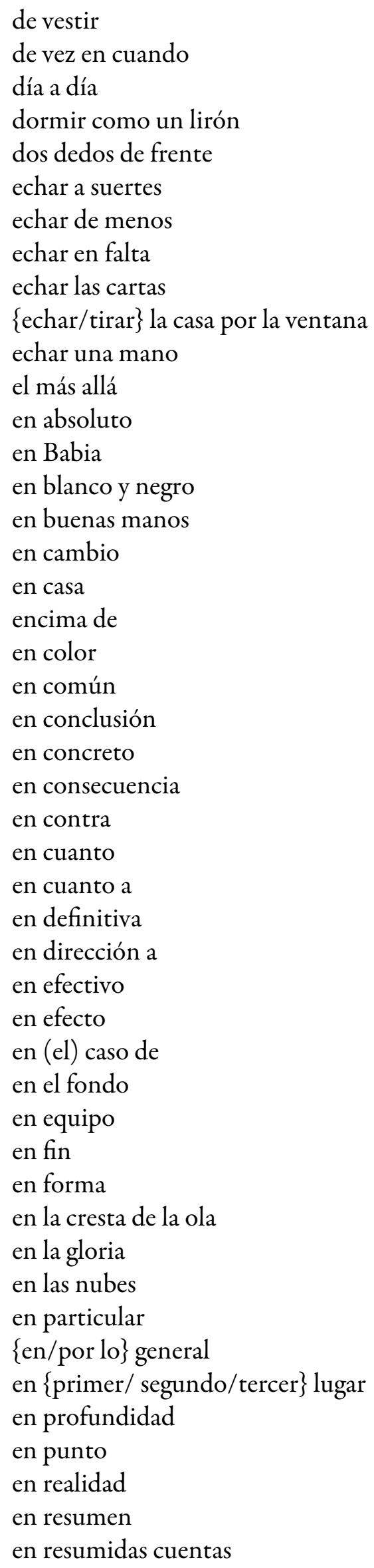


en serio

en suma

en tensión

entre horas

entre la espada y la pared

\{entre/mientras\} tanto

entre Pinto y Valdemoro

en un abrir y cerrar de ojos

en un santiamén

en vísperas

en vista de

en voz alta

en voz baja

escurrir el bulto

estar $\{$ de/en $\}$ oferta

estar en la mano

estar que se cae

$\{$ faltarle/no encontrar/ no tener $\}$ palabras

faltar tiempo

fuera de tiempo

ganar tiempo

gracias a

hacer aguas

hacer caso

hacer cola

hacer el agosto

hacer falta

hacer hincapié

hacer la boca agua

hacer la vista gorda

hacer novillos

hacer oídos sordos

hacer tiempo

hacer (un) favor

hasta ahora

hasta la coronilla

hasta las narices

\{hecho/a\} polvo

\{helársele la sangre/quedarse sin sangre\} (en las venas)

hoy (en) día

ir al grano

ir bien

junto a

las tantas

levantar cabeza

llamar la atención

llevar a cabo 


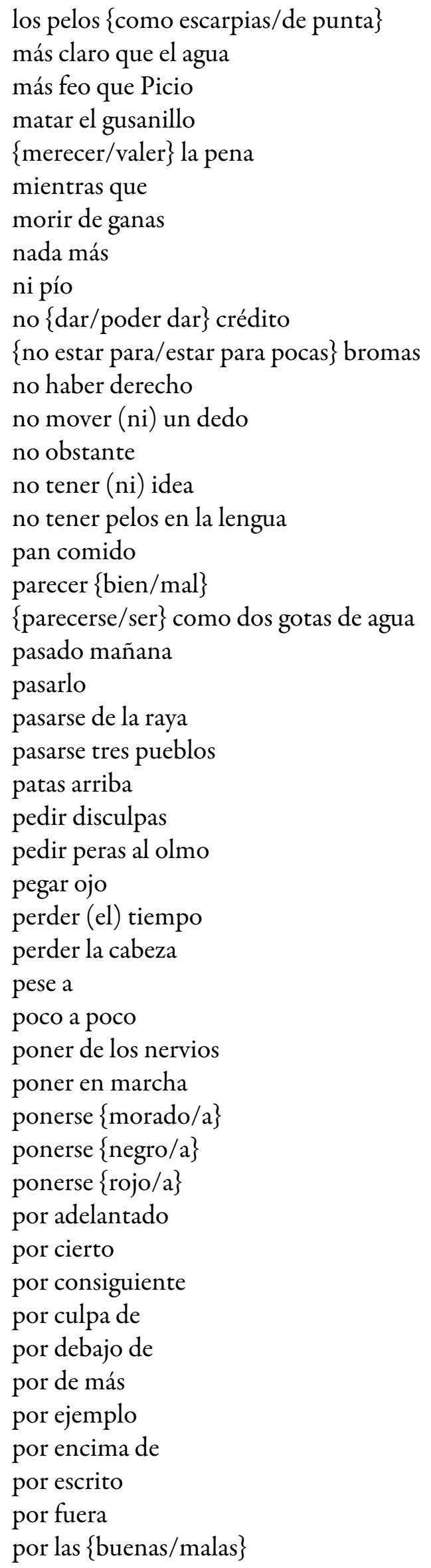




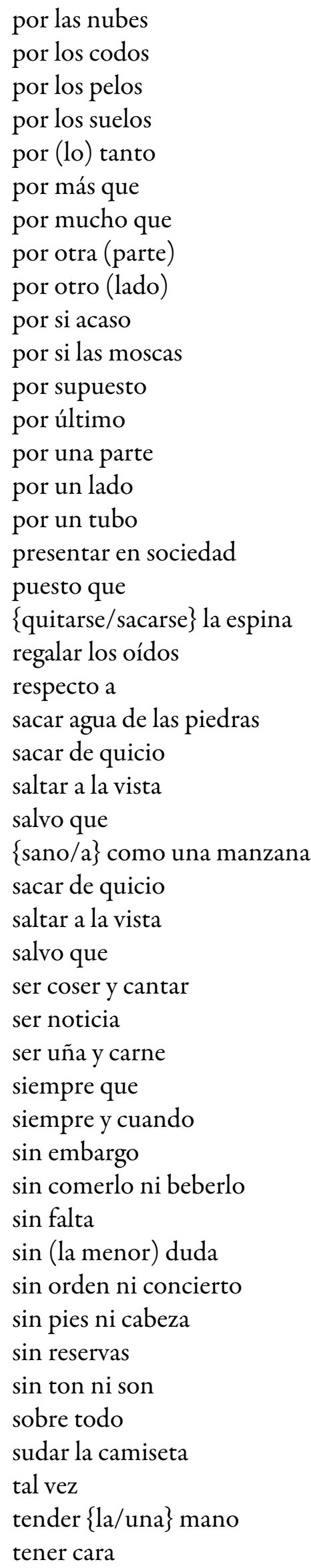




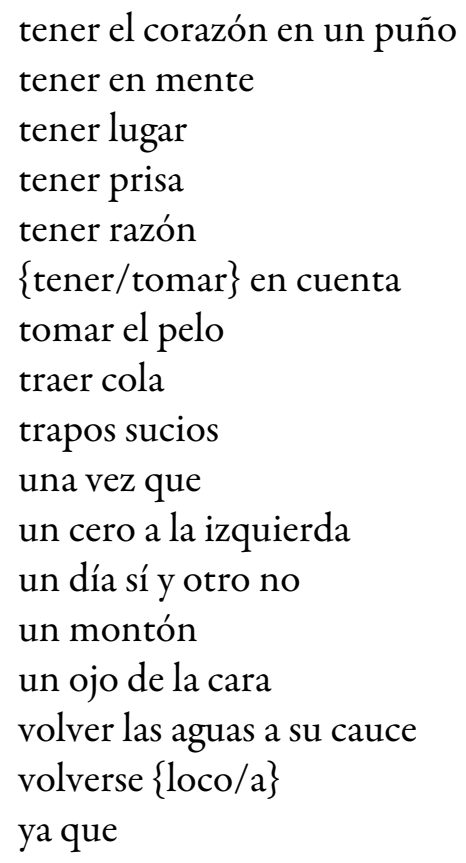

\subsection{MFLELE para el nivel C1-C2}

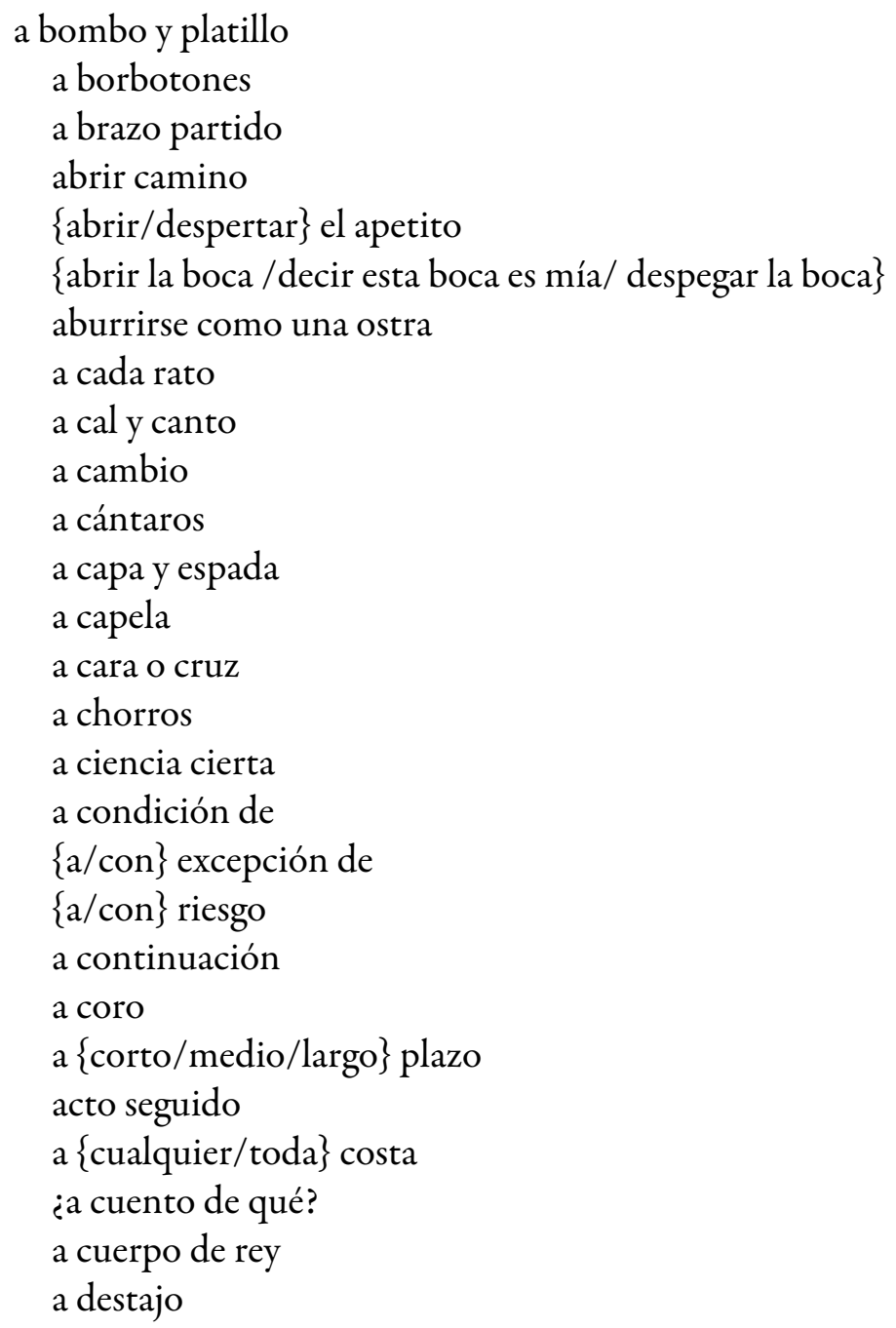




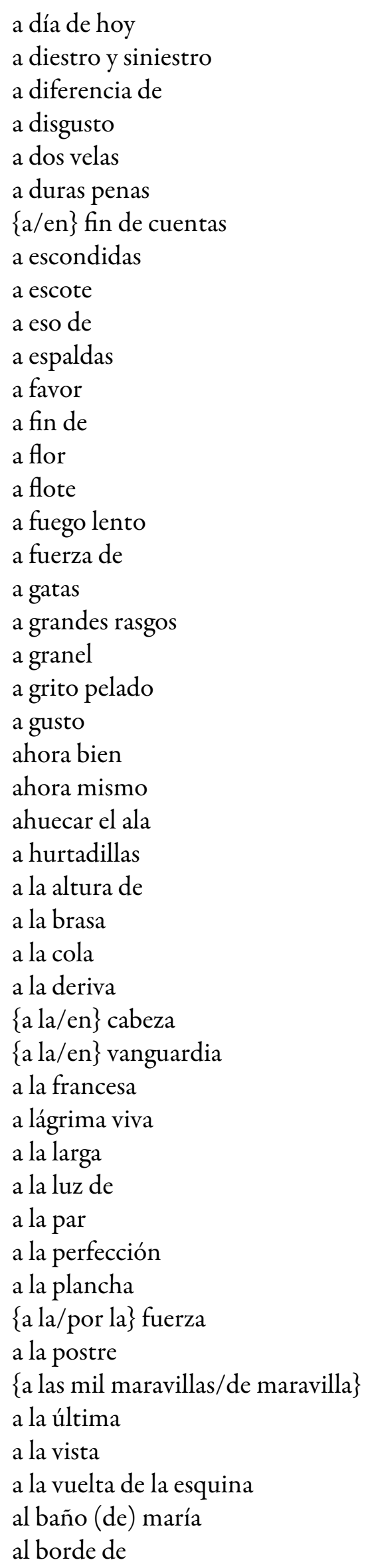




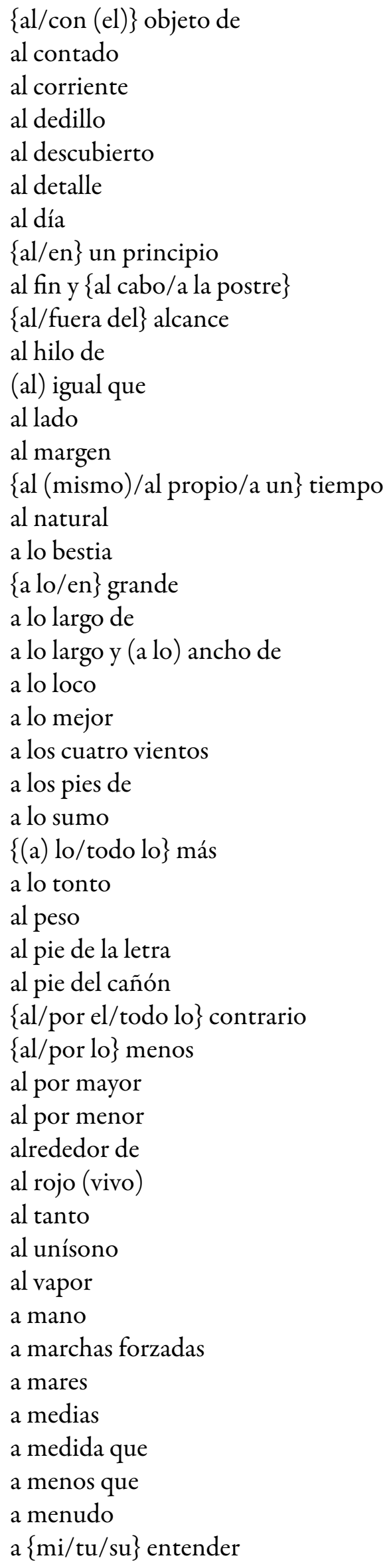




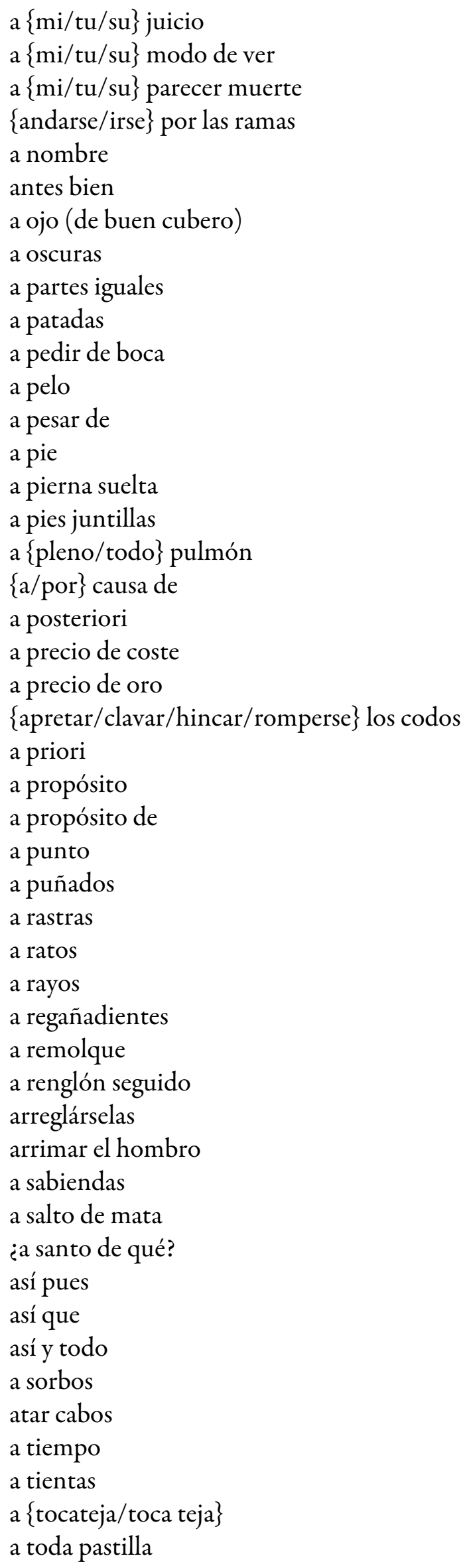




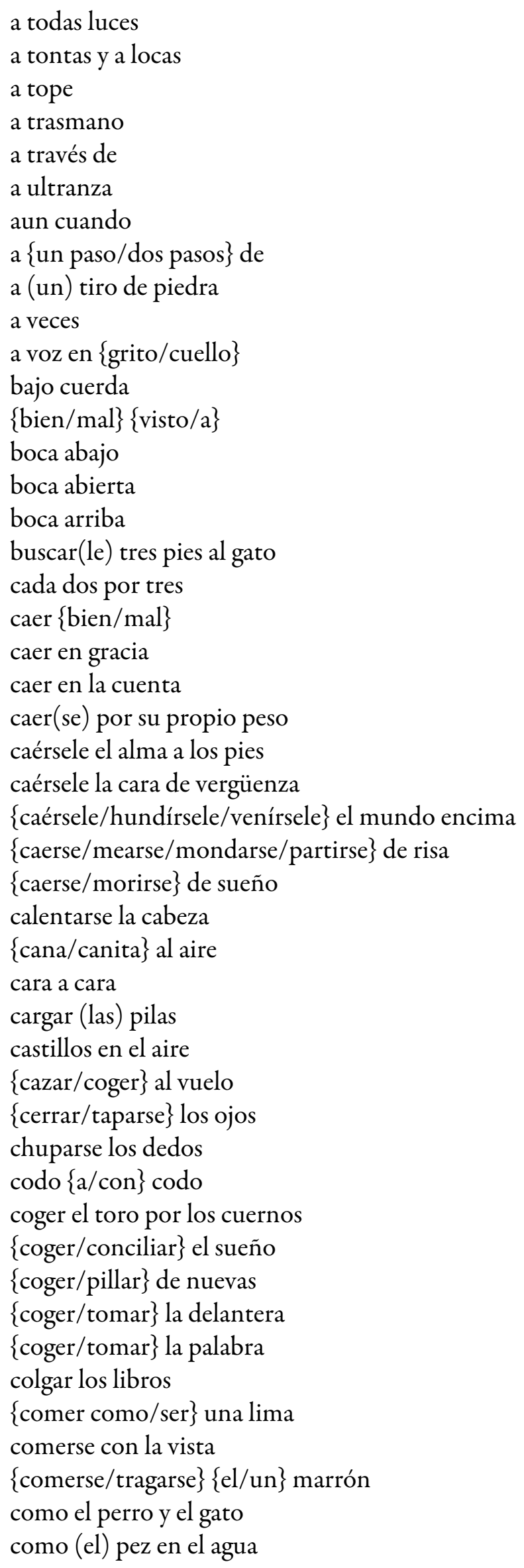




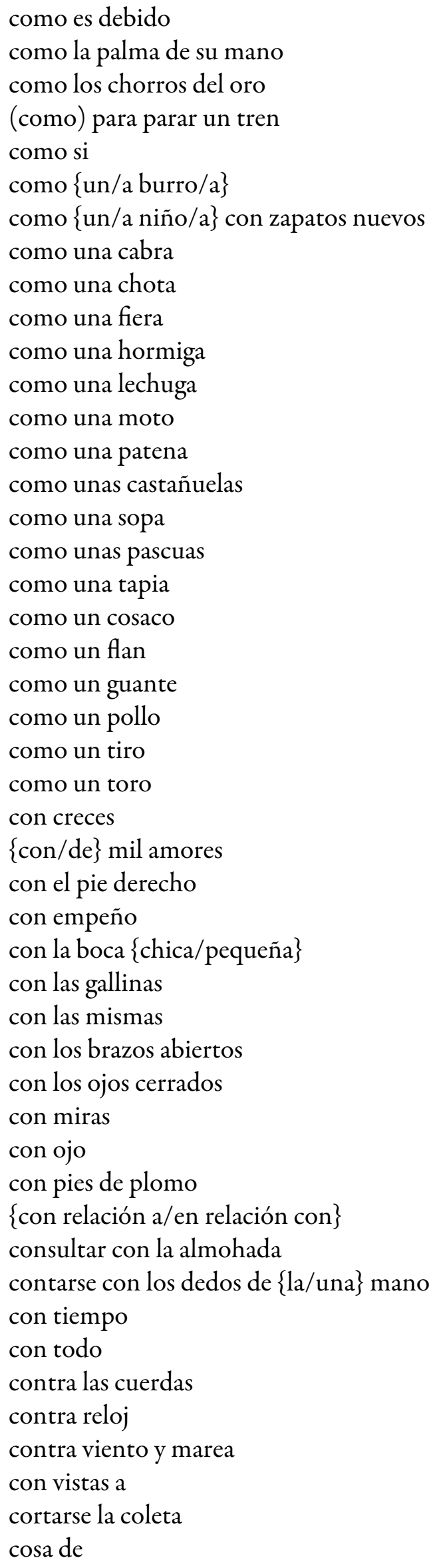




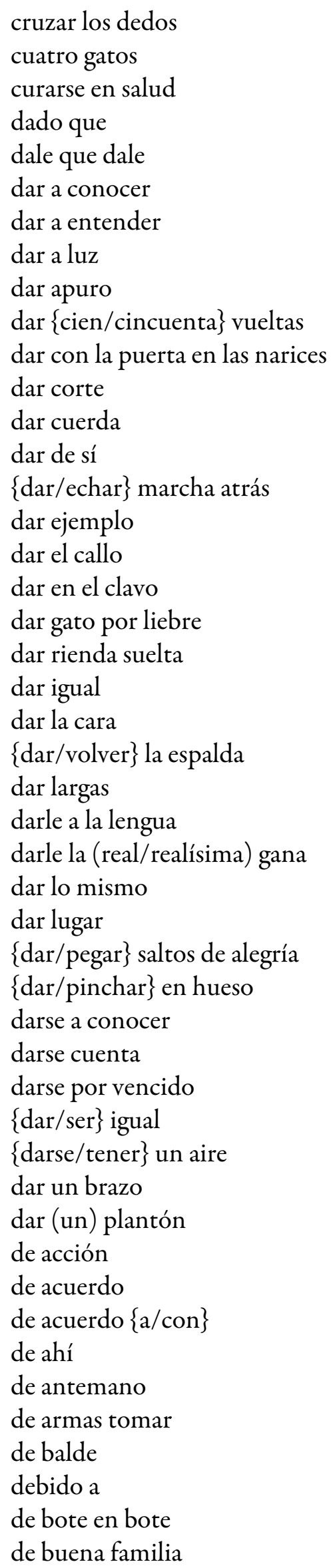




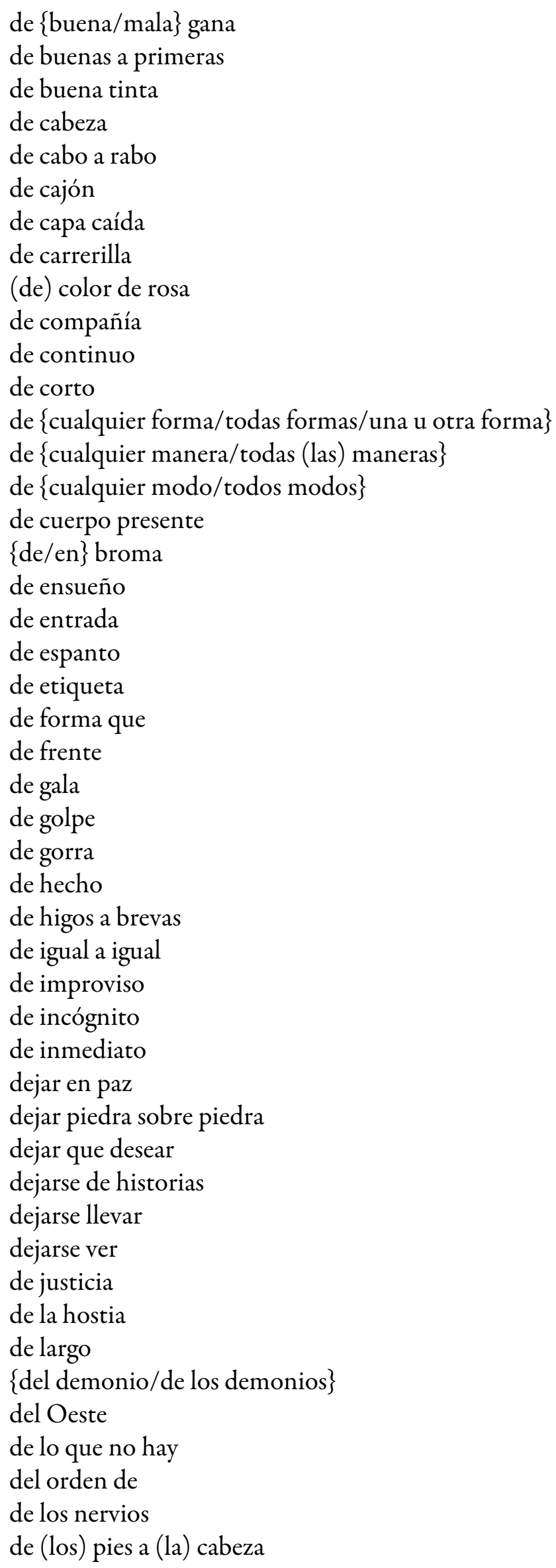




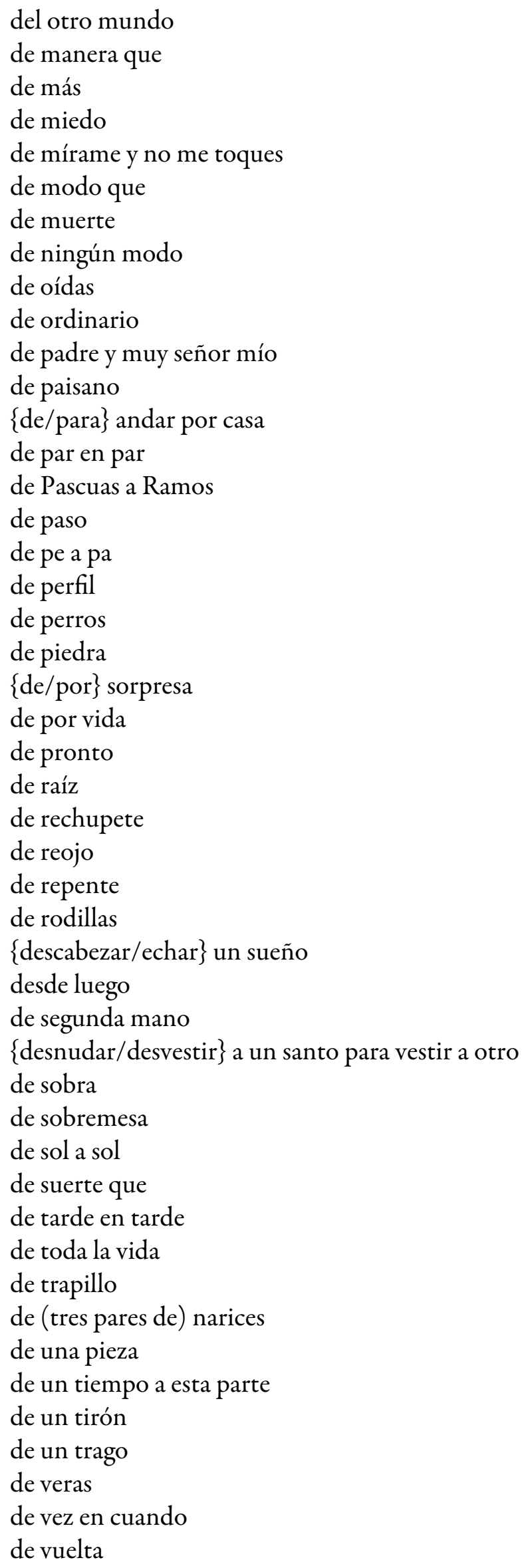




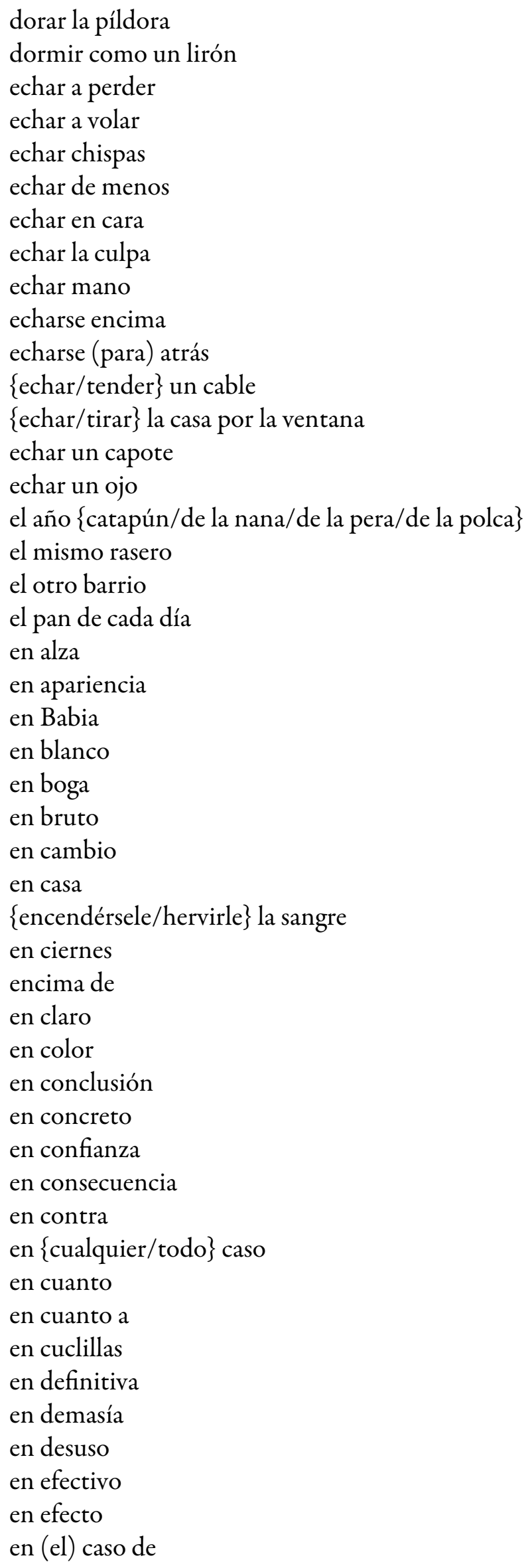




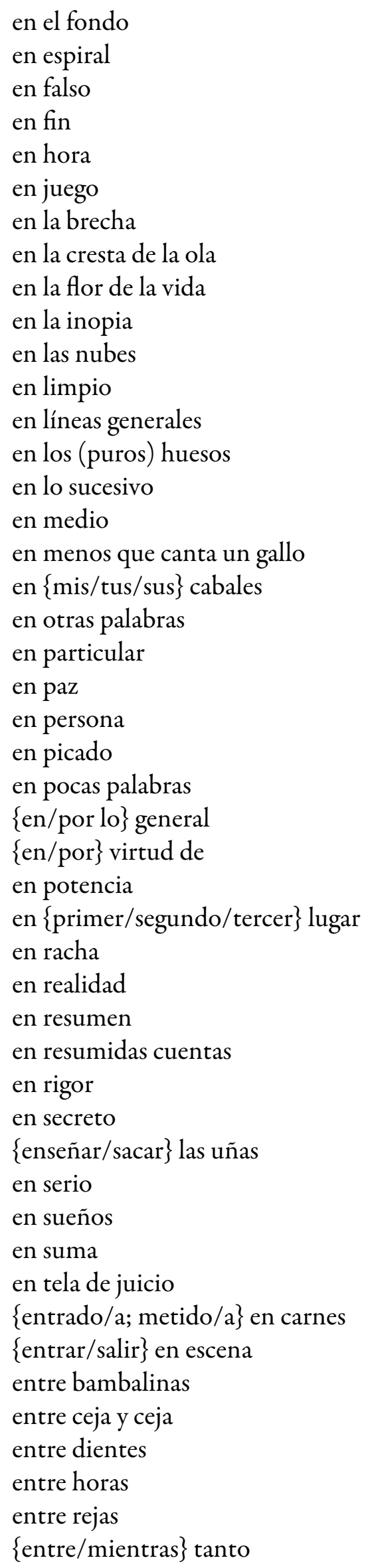


entre pitos y flautas

en un abrir y cerrar de ojos

en un periquete

en un santiamén

en vano

en vela

en vilo

en vista de

en vivo

en voz alta

erre que erre

\{escapar/irse/salirse\} por la tangente

escurrir el bulto

estar a las duras y a las maduras

estar al caer

estar en todo

\{estar/ir $\}$ listo/a $\}$

estar para fiestas

estar $\{$ sembrado/a $\}$

estirar la pata

estirar las piernas

frente a frente

fuera de serie

golpe de vista

gracias a

\{guardar/mantener\} las distancias

haber gato encerrado

haber moros en la costa

hablar claro

hacer acto de presencia

hacer $\{$ buenas/malas migas\}

hacer bulto

hacer el paripé

hacer el vacío

hacer esquina

hacer falta

hacer gracia

hacer la vista gorda

hacer memoria

hacer novillos

hacerse cargo

hacerse de oro

hacérsele la boca

hacerse notar

hacer una de las suyas

$\{$ hacer/venir\} al caso

hasta arriba 


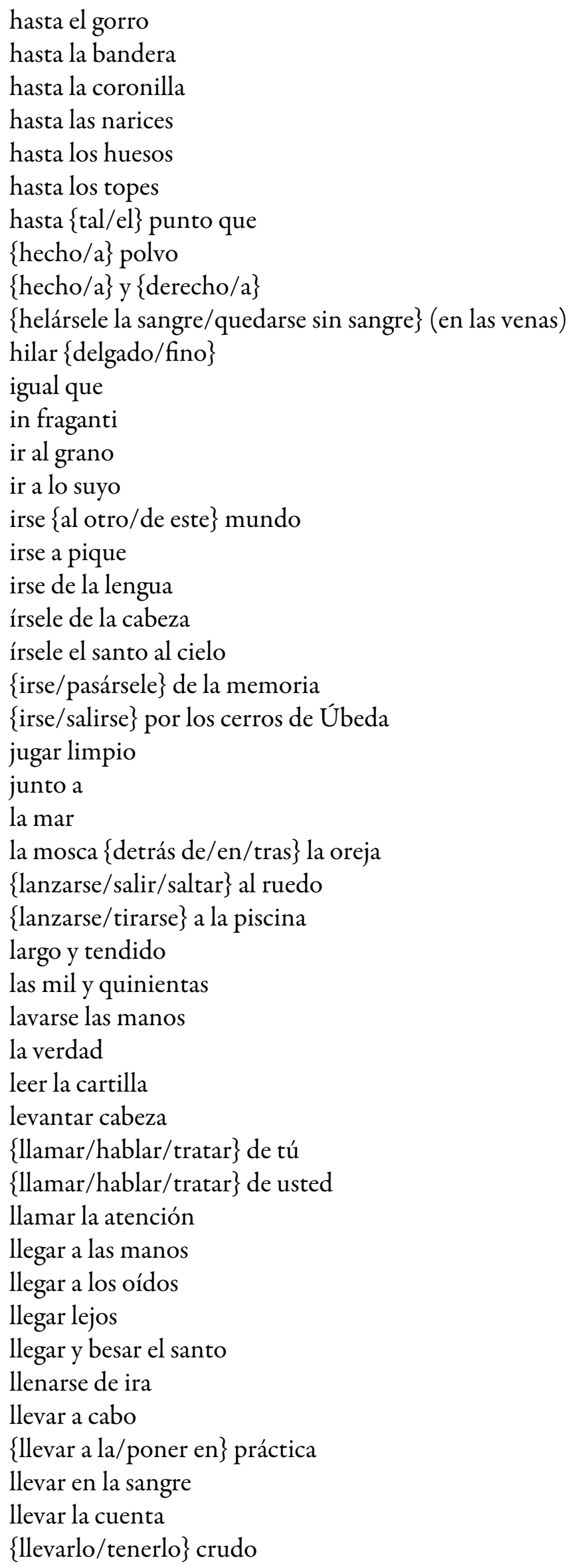




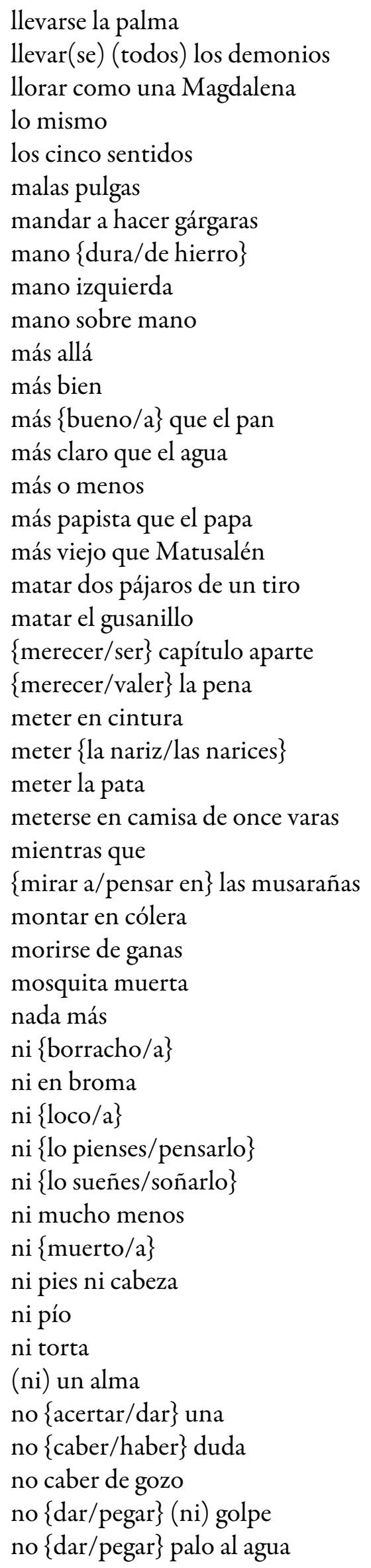




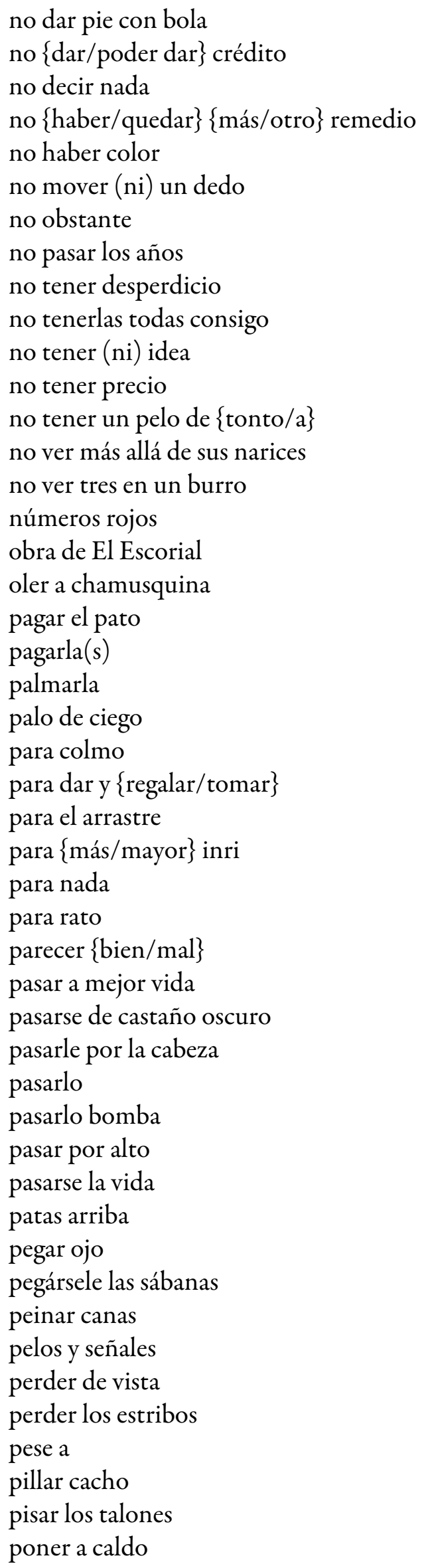




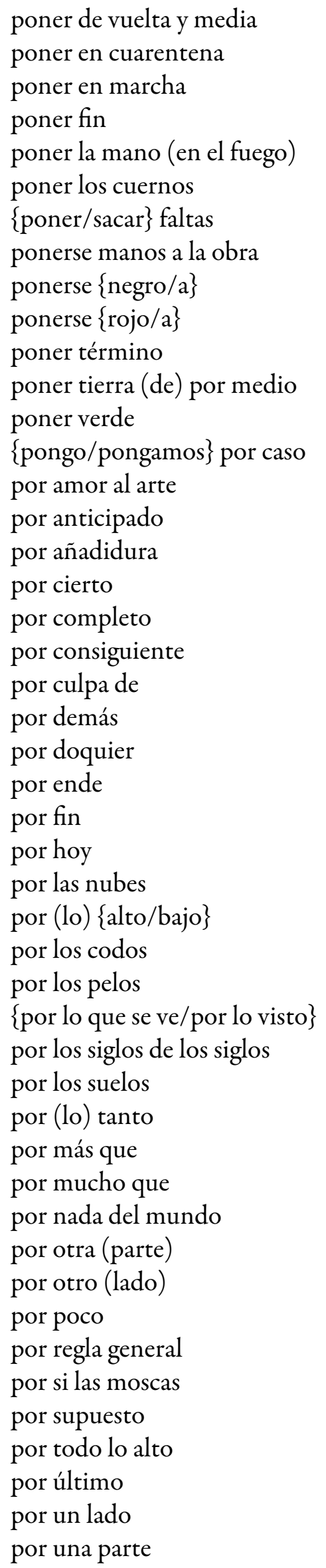




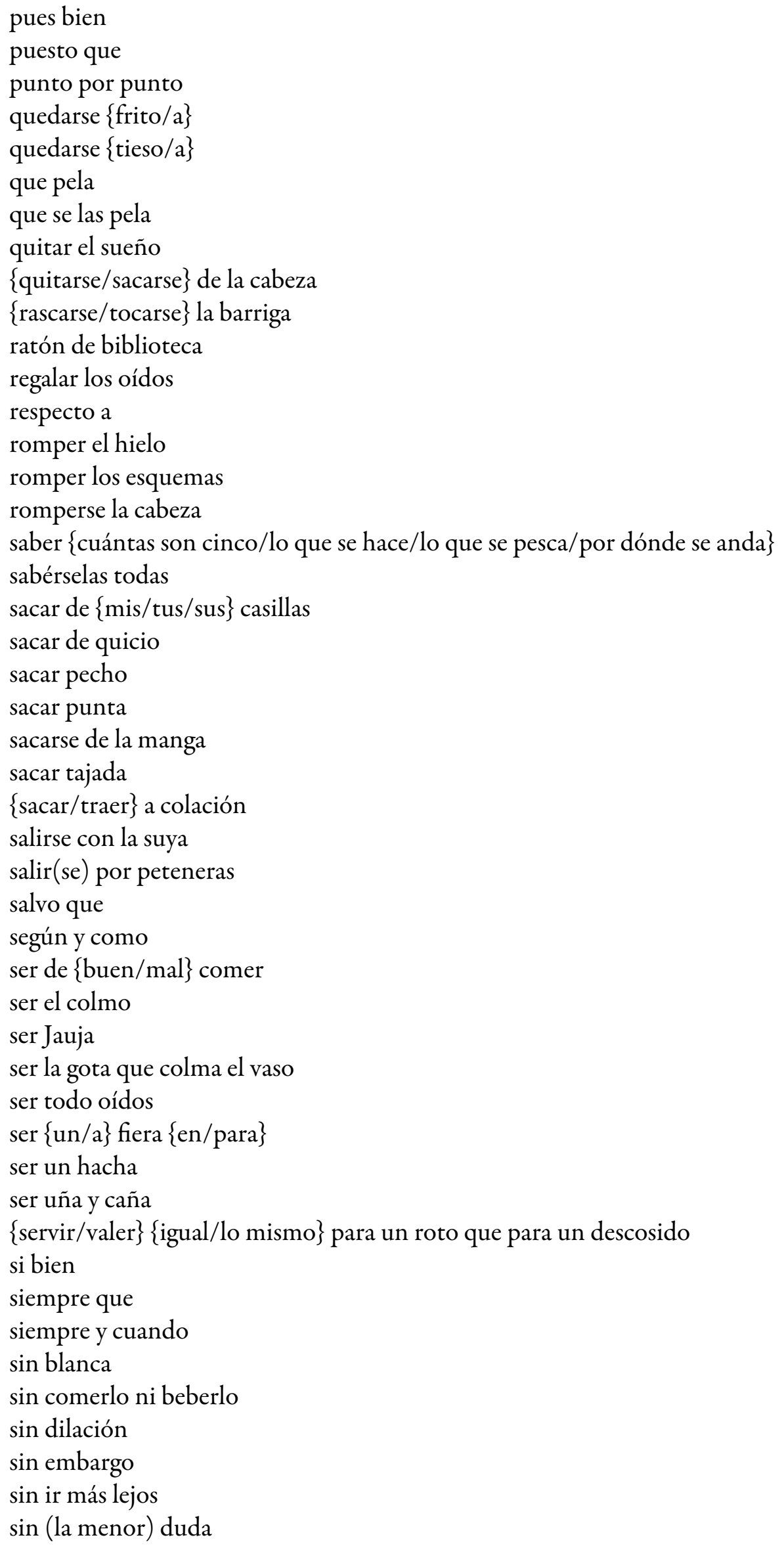




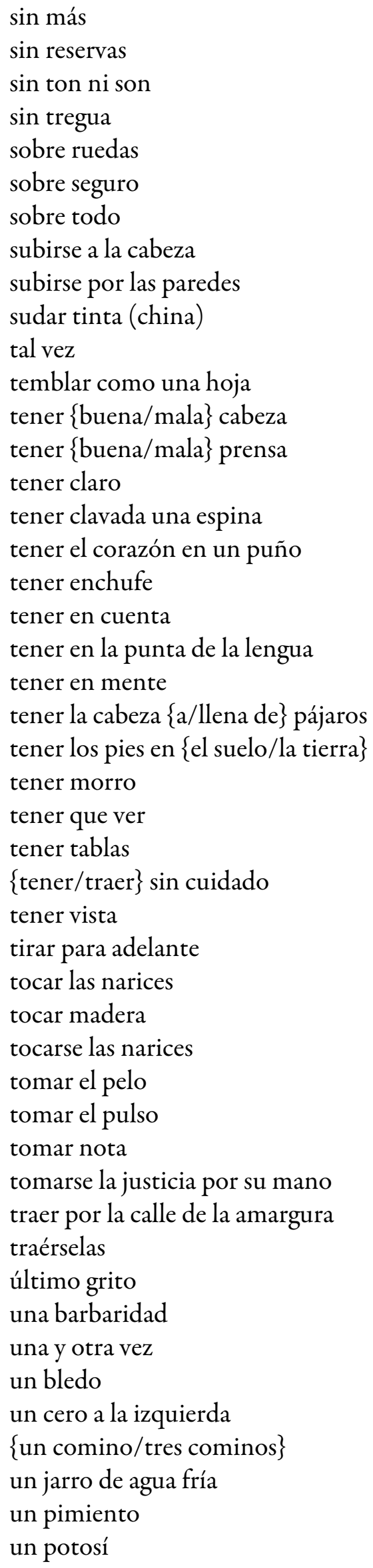




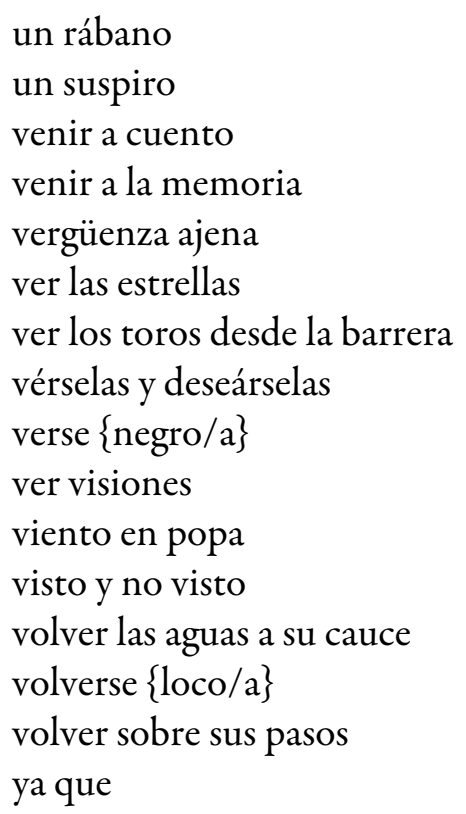

\section{Conclusiones}

En este artículo se ha expuesto el Minimo fraseológico locucional de ELE, el cual abarca, según el nivel lingüístico de los discentes de ELE, las locuciones mínimas de naturaleza actual, frecuente y recomendable del español peninsular para su enseñanza, desde el nivel acceso (A1) al nivel maestría (C2). En lo que atañe a su diseño, se ha postulado una metodología propia, basada en cuatro criterios: (1) extracción de todas las locuciones presentes en 30 manuales generales de ELE, (2) la explotación didáctica de dichas locuciones en, como mínimo, uno de los manuales, (3) la sustracción de todas las locuciones inscritas en los inventarios de Nociones Generales, Nociones específicas y Tácticas y estrategias pragmáticas del PCIC y (4) el registro de todas las locuciones resultantes en, por lo menos, dos de los diccionarios tomados como referencia.

El resultado de la ejecución de nuestra investigación fue un cómputo de 39 locuciones para nivel A, 407 para el nivel B y 843 para nivel C. Cabe aclarar, por lo tanto, que los datos ofrecidos no se ajustan al mínimo fraseológico entendido como aquel conjunto de locuciones que domina un hablante nativo de español estándar en el momento actual sino al estudiante de ELE. De haber sido un mínimo fraseológico locucional de hablantes nativos, se hubieran considerado otros criterios, como los seguidos por Zurdo Ruiz-Ayúcar y Sevilla Muñoz (2016) en su Mínimo paremiológico: la revisión de corpus, las entrevistas a informantes, el rastreo de diccionarios y su respectiva frecuencia, etc. Del mismo modo, tal y como ya apuntó Leal Riol (2011, p. 232), el fin último del MFLELE es el de disponer de "un corpus de unidades fraseológicas que les permita desenvolverse en situaciones cotidianas de comunicación con sus amigos, profesores, familias, viajes y demás”. Con el mismo argumento, Penadés Martínez (2017, p. 335), afirmaría que "llegado a un determinado nivel de conocimiento de la lengua, el alumno puede sentir la necesidad de transmitir los contenidos, sus mensajes, con un cierto grado de expresividad y coloquialidad que, sin duda alguna, puede proporcionar el uso de las locuciones".

En suma, tras la conformación del MFLELE se obtuvieron una serie de conclusiones finales: a) la escasa presencia de locuciones idiomáticas en los manuales seleccionados del nivel A y más aún en lo que respecta a su explotación didáctica, realidad que no sorprende debido a que, de acuerdo con Velázquez Puerto (2018, p. 37), "la correcta extracción del significado idiomático resulta ser más accesible cuanto más próximo se encuentra al significado literal de los elementos que componen la unidad fraseológica"; b) la heterogeneidad en la selección de las locuciones, en especial de las idiomáticas, por parte de las empresas editoriales en los niveles $\mathrm{B}$ y $\mathrm{C}$, puesto que el compendio de locuciones trabajadas de un manual a otro distaba sustancialmente; 
c) la supremacía de las locuciones adverbiales frente al resto de subtipos locucionales en todos los niveles (A, B y C), así en el nivel A, 17 de las 39 locuciones fueron adverbiales, en el nivel B, 185 de las 407, y en el nivel C 347 de las 843; d) la consiguiente escasa presencia de otros tipos de locuciones, concretamente, de las pronominales y de las nominales (por ejemplo, en el nivel A, no se obtuvo resultado alguno de la categoría pronominal; en el nivel B, solo uno; y en el nivel C, únicamente cuatro); y e) el salto desproporcionado en el número de locuciones integradas en el MFLELE entre un nivel lingüístico y otro: 39 locuciones en el nivel A, 407 en el nivel B y 843 en el nivel C.

\section{BibLiografía}

Acquaroni, R., Amenós, J., González, V., Gras, P., Simkievich, J., Soriano, C. y Tarrés, I. (2017). C de C1. Barcelona: Difusión.

Aguilar Lozano, M. J. (2013). Notas sobre las posibilidades de aprendizaje de español mediante unidades fraseológicas. MarcoELE, 17, 1-23.

Alonso Cuenca, M. (2011). Embarque 1. Curso de español lengua extranjera. Madrid: Edelsa.

Alonso Cuenca, M. (2014). Embarque 3. Curso de español lengua extranjera. Madrid: Edelsa.

Alonso Cuenca, M. y Prieto Prieto, R. (2011). Embarque 2. Curso de español lengua extranjera. Madrid: Edelsa.

Alonso Cuenca, M. y Prieto Prieto, R. (2014). Embarque 4. Curso de español lengua extranjera. Madrid: Edelsa.

Álvarez Martínez, M. A., Blanco Canales, A., Gómez Sacristán, M. L. y Pérez de la Cruz, N. (2015). Nuevo Sueña 1. Madrid: Anaya.

Álvarez Martínez, M. A. y Sanz Sánchez, B. (2016). Nuevo Sueña 3. Madrid: Anaya.

Barani, N. (2007). Cincuenta refranes entre los más frecuentes del español actual con su correspondencia en farsi. Paremia, 16, 99-105.

Blanco, A., Fernández, M. C. y Torrens, M. J. (2017). Nuevo sueña 4. Madrid: Anaya.

Borobio Carrera, V. (2002). Nuevo ele Avanzado 4. Madrid: SM.

Borobio Carrera, V. (2009). Nuevo ele inicial 1: curso de español para extranjeros. Madrid: SM.

Borobio Carrera, V. (2010). Nuevo ele inicial 2: curso de español para extranjeros. Madrid: SM.

Borobio Carrera, V. y Palencia del Burgo, R. (2001). Nuevo ele Intermedio 3. Madrid: SM.

Cabrerizo Ruiz, M. A. y Gómez Sacristán, M. L. (2015). Nuevo Sueña 2. Madrid: Anaya.

Castro Viudez, F., Díaz Ballesteros, P., Rodero Díez, I. y Sardinero Francos, C. (2017). Nuevo Español en marcha 1. Madrid: SGEL.

Castro Viudez, F., Rodero Díez, I. y Sardinero Francos, C. (2015). Nuevo Español en marcha 2. Madrid: SGEL.

Castro, F., Rodero, I. y Sardinero Francos, C. (2014). Nuevo Español en marcha 3. Madrid: SGEL.

Castro, F., Rodero, I. y Sardinero Francos, C. (2014). Nuevo Español en marcha 4. Madrid: SGEL.

Chamorro, M. D., Lozano, G., Ríos, A., Rosales, F., Plácido, J. y Ruiz G. (2006). El ventilador. Barcelona: Difusión.

Corpas Pastor, G. (1996). Manual de fraseología española. Madrid: Gredos.

Corpas, J. Garmendia, A. y García, E. (2013). Aula Internacional 2. Barcelona: Difusión.

Corpas, J., Garmendia, A. y Soriano, C. (2013). Aula Internacional 1. Barcelona: Difusión.

Corpas, J. y Garmendia, A. (2014). Aula Internacional 4. Barcelona: Difusión.

Corpas, J. y Garmendia, A. (2015). Aula Internacional 5. Barcelona: Difusión.

Council of Europe. (2001). Common European Framework of Reference for Languages: Learning, Teaching, Assessment. Strasbourg: Council of Europe.

Crida Álvarez, C. C. y Sevilla Muñoz, J. (2015). La problemática terminológica en los estudios paremiológicos. Anuari de filologia. Estudis de lingüistica, 5, 67-77. 
English Cambridge Assessment. (2018). Common european framework of reference for languages: learning, teaching, assessment. Recuperado de https://www.cambridgeenglish.org/es/exams-and-tests/cefr/

Fernández Prieto, M. J. (2004). La enseñanza de la fraseología. Evaluación de recursos y propuestas didácticas. En M. A. Castillo Carballo, O. Cruz Moya, J. M. García Platero y J. P. Mora Gutiérrez (Coords.), Las gramáticas y los diccionarios en la enseñanza del español como segunda lengua: deseo y realidad (pp. 349-356). Sevilla: ASELE/ Universidad de Sevilla.

Forment Fernández, Ma del M. (2000). Hacer novillos, hacer campana o hacer la vaca: ¿qué fraseología enseñar? En M. A. Martín Zorraquino (Coord.), ¿Qué español enseñar?: norma y variación lingüisticas en la enseñanza del español a extranjeros (pp. 317-325). Zaragoza: ASELE/Universidad de Zaragoza.

Gómez Molina, J. (2000). Las unidades fraseológicas del español: una propuesta metodológica para la enseñanza de las locuciones en clase de ELE. Quaderns de Filologia. Estudis Lingüistics, 5, 111-134.

González Rey, M. I. (2012). De la didáctica de la fraseología a la fraseodidáctica. Paremia, 21, 67-84.

Gutiérrez Quintana, E. (2004). La enseñanza de las locuciones a estudiantes de ELE. VIII Congreso Nacional de Lingüistica e Filologia Rio de Janeiro.

Hierro, A., Miranda, F., Peláez S. y Robles, S. (2017). Método 5. Madrid: Anaya.

Instituto Cervantes. (1997-2020). Biblioteca fraseológica y paremiológica. Madrid: Instituto Cervantes. Recuperado de http://cvc.cervantes.es/

Instituto Cervantes. (2006). Plan Curricular del Instituto Cervantes. Niveles de Referencia. Madrid: Instituto Cervantes, Biblioteca Nueva.

Leal Riol, M. J. (2011). La enseñanza de la fraseología en español lengua extranjera. Estudio comparativo dirigido a estudiantes anglófonos. Valladolid: Universidad de Valladolid.

López Vázquez, L. (2011). La competencia fraseológica en los textos de los manuales de ELE de nivel superior. ASELE, Actas XXII, 531-542.

Maldonado González, C. (Dir.) (2012). Clave. Diccionario de uso del español actual [Clave]. Madrid: SM.

Mieder, W. (2016). Prólogo. En Ma I. Zurdo Ruiz-Ayúcar y J. Sevilla Muñoz (Eds.), El mínimo paremiológico: aspectos teóricos y metodológicos (pp. 7-11). Madrid: Instituto Cervantes.

Muñoz-Basols, J. (2016). Enseñanza del lenguaje idiomático. En J. Gutiérrez-Rexach (Ed.), Enciclopedia de lingüistica hispánica (pp. 442-453). Londres/Nueva York: Routledge.

Núñez Román, F. (2015). Enseñar fraseología: consideraciones sobre la fraseodidáctica del español. Didáctica. Lengua y Literatura, 27, 153-166.

Olímpio de Oliveira Silva, M. E., Penadés Martínez, M. I., y Ruiz Martínez, A. M. (2006). Ni da igual, ni da lo mismo. Para conocer y usar las locuciones verbales en el aula de español. Madrid: Edinumen.

Penadés Martínez, I. (2002). Diccionario de locuciones verbales para la enseñanza del español [DICLOCVER]. Madrid: Arco/Libros.

Penadés Martínez, I. (2004). Diccionario de locuciones para la enseñanza del español. Linred: lingüistica en la Red, $1,1-7$.

Penadés Martínez, I. (2005). Diccionario de locuciones adverbiales para la enseñanza del español [DICLOCADV]. Madrid: Arco/Libros.

Penadés Martínez, I. (2008). Diccionario de locuciones nominales, adjetivas y pronominales para la enseñanza del español [DICLOCNAP]. Madrid: Arco/Libros.

Penadés Martínez, I. (2012). Didáctica de la fraseología y de la paremiología. En M. L. Ortiz Álvarez (Org.), Tendências actuáis na pesquisa descritiva e aplicada em fraseologia e paremiología (pp. 91-117). Anais. I, Campinas: Pontes Editores.

Penadés Martínez, I. (2015). La enseñanza de la fraseología vinculada a los contenidos de los manuales de ELE. En P. Mogorrón Huerta y F. Navarro Domínguez (Eds.), Fraseología, Traducción y Didáctica (pp. 241-260). Frankfurt am Main: Peter Lang. 
Penadés Martínez, I. (2017). La enseñanza de las unidades fraseológicas. En A. M. ${ }^{a}$ Cestero Mancera e I. Penadés Martínez (Eds.), Manual del profesor de ELE (pp. 311-355). Alcalá de Henares: Servicio de Publicaciones de la Universidad de Alcalá.

Penadés Martínez, I., Penadés Martínez, R., Xiaojing, H. y Olímpio de Oliveira Silva, E. (2008). 70 refranes para la enseñanza del español. Madrid: Arco/Libros.

Pérez Bernal, M. (2005). Fraseología y metáfora. Materiales para la enseñanza de la fraseología en una L2. En M. A. Castillo Carballo, O. Cruz Moya, J. M. García Platero y J. P. Mora Gutiérrez (Coords.), Las gramáticas y los diccionarios en la enseñanza del español como segunda lengua: deseo y realidad (pp. 646-654). Sevilla: ASELE/ Universidad de Sevilla.

Real Academia Española. (2014). Diccionario de la lengua española [DLE]. Madrid: Espasa-Calpe.

Ruiz Martínez, A. M. (2005). Las unidades fraseológicas vinculadas con las funciones pragmáticas del nivel Plataforma y del nivel Umbral en el Marco común europeo de referencia para las lenguas: aprendizaje, enseñanza, evaluación. ASELE, Actas XVI, 569-579.

Ruiz, J., Suárez, E., Muñoz, J. y Del Mazo de Unamuno, M. (2012). Nuevo Prisma C2. Madrid: Edinumen.

Seco, M., Andrés, O. y Ramos, G. (2018). Diccionario fraseológico documentado del español actual. Locuciones y modismos españoles [DFDEA]. Madrid: Aguilar.

Serralde, B., Casarejo, E., López, M. y Martínez, D. (2016). Vitamina C1. Madrid: SGEL.

Sevilla Muñoz, J. (1996). Sobre la paremiología española. Euskera: Trabajos y actas de la Real Academia de la Lengua Vasca, 16(3), 641-672.

Sevilla Muñoz, J. (2010). Los aspectos fraseográficos del proyecto de investigación El mínimo paremiológico. En C. Mellado, P. Buján, C. Herrero, N. Iglesias y A. Mansilla (Eds.), La fraseografía del S. XX. Nuevas propuestas para el español y el alemán (pp. 231-248). Berlín: Frank \&Time.

Solano Rodríguez, M. A. (2007). El papel de la conciencia fraseológica en la enseñanza y aprendizaje de una lengua extranjera. En M. ${ }^{a}$ I. González Rey (Ed.), Les expressions figées en didactique des langues étrangères (pp. 201-221). Louvain-La- Neuve: Intercommunication et E.M.E.

Szyndler, A. (2015). La fraseología en el aula de E/LE: ¿un reto difícil de alcanzar? Una aproximación a la fraseodidáctica. Didáctica. Lengua y Literatura, 27, 197-216.

Timofeeva, L. (2013). La fraseología en la clase de lengua extranjera: ¿misión imposible? Onomázein, 28, 320-336.

Velázquez Puerto, K. (2018). La enseñanza-aprendizaje de fraseología en ELE. Madrid: Arco / Libros.

Verdía, E. (Coord.), Fontecha, M., Fruns, J., Martín, F. y Vaquero, N. (2010). En acción 3. Madrid: EnClave.

Verdía, E. (Coord.), Fruns, J., Martín, F., Ortín, M. y Rodrigo, C. (2005). En acción 2. Madrid: EnClave.

Verdía, E. (Coord.), González, M., Martín, F., Molina, I., Rodrigo, C. y Tudela, N. (2010). En acción 1. Madrid: EnClave.

VV. AA. (2012). Nuevo Prisma C1. Madrid: Edinumen.

VV.AA. (2014). Aula Internacional 3. Barcelona: Difusión.

Vyshnya, N. (2008). Mínimo paremiológico ucraniano y peculiaridades de su traducción. Paremia, 17, 101-109.

Zurdo Ruiz-Ayúcar, Ma I. y Sevilla Muñoz, J. (2016). Elminimoparemiológico: aspectos teóricos y metodológicos. Madrid: Instituto Cervantes.

\section{Notas}

1 Según Corpas Pastor (1996), las unidades fraseológicas quedan dividas en tres esferas: colocaciones, locuciones y enunciados fraseológicos.

2 Esta realidad se enfrenta, sorprendentemente, a la consideración explícita que reciben las unidades fraseológicas en los exámenes DELE, por ejemplo (Penadés Martínez, 2017, p. 333).

3 Entiéndase por fraseodidáctica "no solo como la didáctica de la fraseología de una lengua sino también como la didáctica de toda una lengua a través de su fraseología” (González Rey, 2012, p. 67). 
4 Leal Riol (2011, pp. 227-233) detalló cinco criterios para la selección de las unidades fraseológicas en el aula de ELE: la frecuencia, la facilidad/dificultad, los factores culturales, la rentabilidad y la productividad, y necesidad y los intereses del alumnado.

5 Aguilar Lozano (2013, p. 4), pese a no presentar de manera específica qué unidades fraseológicas han de tener vida dentro del aula, proporcionó tres criterios en los cuales se apoyaba su diseño de material de trabajo de las locuciones: la alta idiomaticidad, el nivel de uso coloquial y su alta frecuencia. Estos criterios han supuesto, por ende, otro punto de partida en la construcción del MFLELE.

6 La paremiología ha de entenderse como "subdisciplina fraseológica cuya función versa sobre el estudio y el análisis de todo aquello cuanto acontece sobre las paremias” (Crida Álvarez, Sevilla Muñoz, 2015, p. 68).

7 El mínimo paremiológico, según anunció Sevilla Muñoz (2010, p. 239), se componía de 1600 paremias.

8 Se ha de destacar que Penadés Martínez et al. (2008) sobresale, precisamente, por no tratarse de un refranero reducido a una simple compilación de refranes y que no siempre supone su elaboración lexicográfica).

9 Por ejemplo, A buen entendedor pocas palabras bastan 1. La persona inteligente comprende fácilmente lo que se le dice. 2. No hay necesidades de dar explicaciones ni de decir expresamente lo que se alude. (Penadés Martínez et al., 2008, p. 17).

10 Esta editorial se tuvo en cuenta únicamente para el corpus del nivel C1-C2. Esta actuación se tomó por el escaso material publicado en los niveles superiores en comparación con los niveles iniciales e intermedios.

11 Es aquí donde se encontraron locuciones de diferentes variedades hispanoamericanas. Dichas locuciones, por ende, fueron rechazadas por dos criterios: el primero, por no contemplarse en este corpus otra variedad del español que la peninsular; el segundo, por no recibir una explotación propiamente didáctica en los manuales.

$12 \mathrm{Al}$ igual que sucedía en el nivel A, se dieron casos en los que una misma locución, en función del contexto de aparición, podría ser incluida dentro de una categoría gramatical u otra. Se indica esta circunstancia mediante el empleo del signo ortográfico secundario de la barra (/).

13 Para su interpretación véase la información recogida en la nota al pie de página número 12. 